\title{
The role of metal powder properties on the tribology of cold sprayed Ti6Al4V-TiC metal matrix composites
}

\author{
Venkata Naga Vamsi Munagala and Richard R Chromik* \\ Department of Mining and Materials Engineering, McGill University, Montreal, QC H3A 0C5, \\ Canada \\ *Corresponding author - Telephone: +1 (514) 398-5686; Fax: +1 (514) 398-4492 \\ Email address: richard.chromik@mcgill.ca
}

\begin{abstract}
Ti6A14V-TiC metal matrix composite (MMC) coatings were cold sprayed using spherical and irregular Ti6A14V powders manufactured with plasma gas atomization and the Armstrong process, respectively. Composite coatings deposited using irregular powders showed higher ceramic retentions and lower porosity compared to spherical powders coatings. Sliding wear tests were performed at two different normal loads using a spherical WC-Co ball as counterface. Wear test results showed that at similar ceramic contents, spherical powder (SP) composites exhibited abrasive wear mechanisms with high coefficients of friction $(\mathrm{CoF})$ and wear rates. In irregular powder (IP) composites, islands of tribolayers, comprised of fragmented $\mathrm{TiC}$ and $\mathrm{TiO}_{2}$ particles, resisted the localized shear deformation leading to low wear, and with free carbon from the TiC particles also lowered the CoF. Increase in ceramic content in the IP MMCs to $23 \%$ led to higher coverage of wear track area with tribolayers and further lowered the wear rate. At higher load, $23 \% \mathrm{TiC}$ composite coatings showed a more continuous tribolayer, whereas lower ceramic content MMCs showed no significant formation of tribolayers. The formation of a highly continuous tribolayer at higher load (in 23\% TiC MMC), led to extremely low $\mathrm{CoF}(\sim 0.25)$ compared to other coatings along with low wear rate. Electron channel contrast imaging and transmission electron microscopy analysis of the worn subsurface under the tribolayers showed coarse-grain microstructures compared to the bare regions of the wear track (i.e. without tribolayer coverage).
\end{abstract}


The formation of coarser grain microstructures indicated less stress transfer to the subsurface both due to the high hardness and lubricating nature of the tribolayers.

Keywords : Metal matrix composites, Ti6Al4V-TiC, Cold spray, Tribolayer, Third bodies, Subsurface microstructure

\section{Introduction}

To improve the tribological properties of $\mathrm{Ti}$ and its alloys, hard particles are added as reinforcements to make metal matrix composites (MMCs), which are fabricated both as bulk parts and coatings [1-5]. The presence of hard phases in the metallic matrix facilitates the formation of stable, continuous and coherent tribolayers that resist plastic deformation during wear process and improve the tribological performance of the material [6,7]. Traditionally MMC coatings were deposited using laser cladding, thermal spray processes like plasma spraying, high velocity oxyfuel spraying etc. [3,8-11]. These processes involve high processing temperatures resulting in phase transformations, formation of brittle intermetallic phases, oxidation, porosity and tensile residual stress buildup. To overcome these limitations, a low temperature and high velocity process known as cold spray (CS) has been used to deposit metals, composites, and heat sensitive materials as thick coatings [12-16]. In CS, micron sized powder particles impact on a substrate at supersonic velocities. During impact, particles experience high strain rates (in the order of $10^{9} \mathrm{~s}^{-1}$ ) at the contact interface that leads to material jetting, adiabatic shear stabilities and subsequently metallurgical bonding [17]. Since it is a solid-state deposition process, the deleterious effects of phase transformations and thermal oxidation, are minimized or eliminated [16]. For the CS deposition of MMCs, metal and ceramic particles either mechanically blended or composite

powders consisting of agglomerated metal and ceramic particles are used as feedstock [2,18]. In addition to these, recently, dual feeding system is being used to simultaneously feed two different powders. This helps to avoid the problems associated with pre-mixing of the powders [12]. In all the above cases, during deposition, the metal particles plastically deform, while the ceramic particles get embedded and entrapped between the metal particles [19].

In case of pure metals or alloys, during tribological interactions, plastic deformation, adhesive transfer, surface oxidation, mechanical mixing between the surfaces, often lead to the formation 
of third bodies. Specifically during dry sliding, tribo-oxidation generally leads to the formation of an oxide film that grows to a critical thickness (as sliding progresses), becomes unstable, and finally gets fragmented [20]. This exposes the underlying nascent metal to the sliding interface while the fragmented oxide particles act as abrasives and promote ploughing resulting in high friction and wear rates. Studies from literature illustrate that reinforcement of ceramic particles into the metallic matrix generally leads to better wear resistance compared to unreinforced matrix. However, unfavourable properties, such as low strength of matrix or poor bonding between metal and reinforced ceramic particles, might result in excessive pullout from the matrix during wear and subsequently lead to high wear rates due to three-body abrasion [21]. The tribological properties of MMCs are mainly influenced by cohesion between particles (metal-metal and metalceramic), ceramic content, ceramic particle size, morphology, and their distribution in the matrix [2,21-26]. During sliding wear of MMCs, plastic deformation of the metallic matrix and dislodging of the reinforced particles, their fragmentation result in the formation of wear debris. These wear debris typically comprise of metallic or oxide particles of the matrix material and fragmented carbide particles. As the sliding progresses, mechanical mixing, tribo-chemical reactions, and agglomeration of wear debris result in the formation of tribolayers. These tribolayers are often stable and hard due to the presence of fragmented ceramic particles and resist the localized shear deformation and decrease wear. The ability of MMCs to form tribolayers can depend strongly on the size of the ceramic particles $[20,25]$. Particles with a size that is equal to or less than the critical oxide thickness of the matrix generally get carried with the fragmented oxide particles while the larger ceramic particles remain intact and contribute to the formation of tribolayers [25].

Using CS, we have studied previously the incorporation of TiC particles into Ti alloys, including cp-Ti [2] and more recently Ti6Al4V-TiC [27]. In the original work on Ti-TiC, the composites were tested for sliding wear using a spherical WC-Co counterface at a normal load of $0.5 \mathrm{~N}(\sim 0.5$ GPa initial maximum Hertzian contact stress). The TiC particles made by plasma atomization provided load support and also solid lubrication, as the particle contained "free carbon" at the dendritic regions. However, considering the limited applications for cp-Ti in the industry, Ti6A14V-TiC composites were the next logical step. In this instance, alloy particles of two different morphologies were studied. The martensitic lath microstructure of the plasma gas atomized powders results in poor particle deformability and porosity in the final deposits, hence a 
more deformable powder with equiaxed microstructure was found as an alternative. In our previous study [27] of cold sprayed Ti6Al4V-TiC MMCs, their tribological behavior was tested at different temperatures and at a higher load of $2.5 \mathrm{~N}(\sim 0.8 \mathrm{GPa}$ initial maximum Hertzian contact stress) using a spherical WC-Co as counterface. Based on the study, it was found that the reinforcement of carbide particles improved the wear resistance at lower temperatures whereas tribo-oxidation led to low wear of both metal and composite coatings at elevated temperatures. However, the influence of ceramic volume fraction and the influence of coating properties on the tribology was not studied extensively at room temperature. In the present study, Ti6Al4V-TiC MMCs were deposited using two morphologically and microstructurally distinct metal powders. Subsequently, sliding wear tests were performed on one set of composite coatings with similar ceramic contents (deposited using the two powders) and another with higher ceramic content at two different normal loads. Electron channel contrast imaging (ECCI) and transmission electron microscopy (TEM) analysis of the third bodies was performed to understand their microstructure and tribo-chemical phases formed. Nanoindentation was done to characterize the mechanical properties of the third bodies.

\section{Experimental procedure}

Grit blasted mild steel plates of dimensions $75 \times 75 \times 3 \mathrm{~mm}^{3}$ that were de-greased before deposition were used as substrates. In the present study, Ti6Al4V-TiC MMC coatings were deposited using two morphologically and microstructurally distinct Ti6A14V powders along with TiC powders (spherical morphology). The Ti6A14V powders of irregular morphology manufactured using Armstrong process had an average particle diameter $\sim 38 \mu \mathrm{m}$ while the SP manufactured using plasma gas atomization process had an average diameter $\sim 31 \mu \mathrm{m}$. The TiC powders had an average diameter $\sim 40 \mu \mathrm{m}$. The size distribution of the powders determined using a laser scattering particle size distribution analyzer (LA-920, Horiba, Japan) is shown in Fig. 1. The microstructure, and detailed characterization of the powders are reported in our previous publications [2,14]. Two different metal-ceramic compositions i.e. 35 vol.\% TiC and 50 vol.\% TiC mixed with irregular Ti6A14V powders were sprayed, whereas one mixture i.e. 50 vol.\% TiC with spherical Ti6Al4V powder was sprayed. To deposit composite coatings, a dual feeding system with two powder hoppers was used to simultaneously feed metal and ceramic powders, where the feed rate of each powder could be controlled and varied independently. This helped to avoid problems such as 
segregation and mechanical damage to the powders that are associated with the mechanical premixing of the powders of different densities. The feed rates of the two powder feeders were adjusted to obtain the desired metal-ceramic mixture. For the deposition of SP composites the total feed rate (metal + ceramic powder) was fixed at $32 \mathrm{~g} \cdot \mathrm{min}^{-1}$, whereas for IP it was $20 \mathrm{~g} \cdot \mathrm{min}^{-1}$. The irregular powders had lower apparent density compared to spherical powders, and were fed at a lower feed rate. This was done both to avoid nozzle clogging and approximately obtain similar volume flow rate (at the inlet of the nozzle) in case of both powders despite differences in apparent densities. All coatings were deposited using a commercially available PCS 800 cold spray system (Plasma Giken, Japan). The working gas was nitrogen and was pressurized and preheated to $4 \mathrm{MPa}$ and $800^{\circ} \mathrm{C}$ prior to flowing through a de Laval nozzle used to obtain supersonic velocities. The stand-off distance between the nozzle and the substrate was $40 \mathrm{~mm}$ while the gun traverse speed was $200 \mathrm{~mm} \cdot \mathrm{s}^{-1}$.

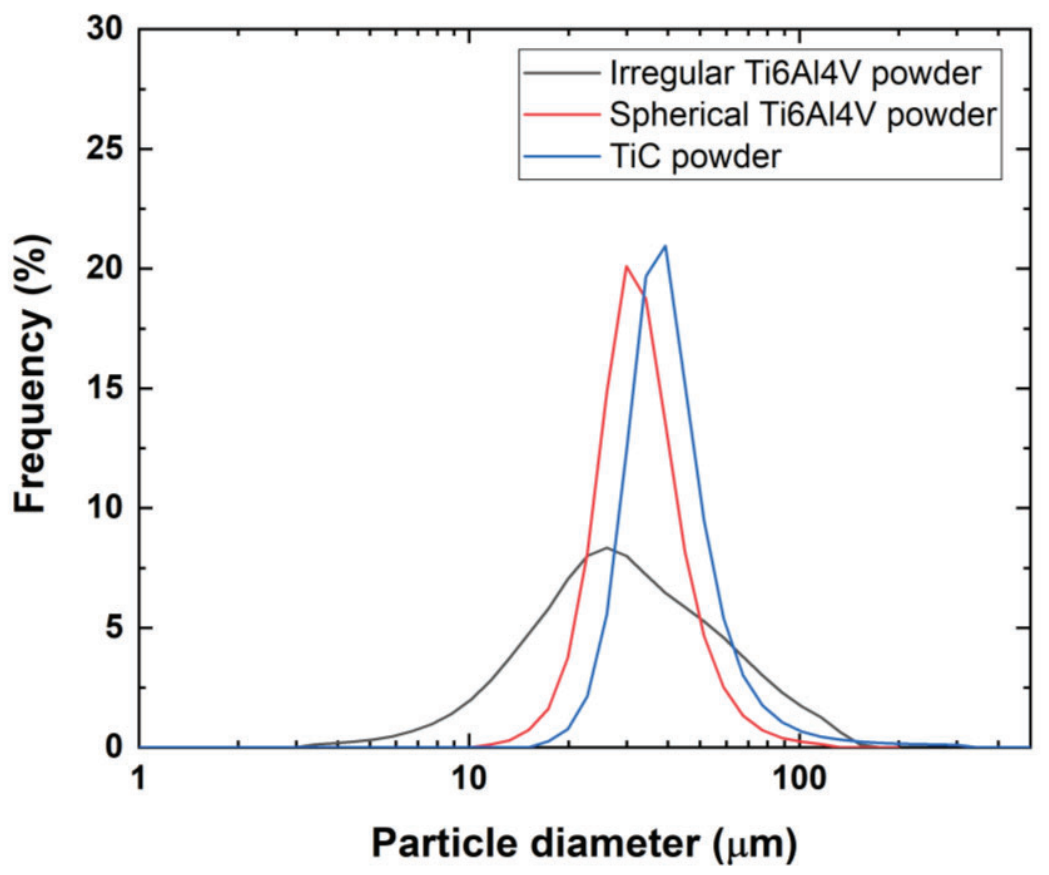

Fig. 1. Particle size distribution of the powders 
After the deposition, the coatings were mechanically cross-sectioned perpendicular to the gun traverse direction and cold mounted in epoxy. These specimens were ground using $\mathrm{SiC}$ abrasive papers from 240 grit to 1200 grit and subsequently polished using polycrystalline diamond suspension of $9 \mu \mathrm{m}, 3 \mu \mathrm{m}$ and $1 \mu \mathrm{m}$. As a final step, the specimens were polished using a vibrometer filled with colloidal silica suspension solution of $0.05 \mu \mathrm{m}$. The polished samples were examined under a scanning electron microscope (SEM) (SU3500, Hitachi, Japan) equipped with a backscattered electron (BSE) and energy dispersive spectroscope (EDS) detectors. BSE images were taken at different locations and were uploaded into ImageJ software. The intensity threshold associated with pores and ceramic particles was adjusted to determine the area fraction of porosity and ceramic retention in the coatings. The measured area fraction was assumed as volume fraction in the present study. At least ten images were analyzed to calculate the final average values. To determine the mean free path (MFP) between the ceramic particles, random lines were drawn on BSE images and the number of particles that intersected the line, per unit length $\left(\mathrm{N}_{1}\right)$ were determined. This value together with the volume fraction of ceramic retained in the coating $\left(\mathrm{v}_{\mathrm{p}}\right)$ was used to determine MFP $(\lambda)$ using Eq. 1 [24,28]:

$$
\lambda=\frac{1-\mathrm{v}_{\mathrm{p}}}{\mathrm{N}_{\mathrm{l}}}
$$

The hardness of the coatings was determined by performing microhardness tests using a Vickers microhardness tester (Buehler, USA) on the polished top surface at a load of $5 \mathrm{~kg}$ and at a holding time of $15 \mathrm{~s}$. Indentation was done at ten different locations to determine the average final hardness value.

Composite coatings were polished till the last step using $0.05 \mu \mathrm{m}$ colloidal suspension solution in a similar manner to that of the coating cross-sections prior to wear test. Reciprocating sliding wear tests were performed in dry air environment (humidity $<2 \%$ ) using a custom-built reciprocating ball-on flat tribometer. The tribometer arm with the counterface and the specimen were enclosed in a high-density polyethylene enclosure (HDPE) that was equipped with a thermohygrometer to continuously monitor the humidity. Dry air was purged into the HDPE enclosure to achieve the low humidity level. Wear tests were performed using a WC-Co spherical counterface (McMaster Carr, USA) of $6.35 \mathrm{~mm}$ diameter at two different normal loads $0.5 \mathrm{~N}$ and $2.5 \mathrm{~N}$ respectively. The sliding speed was $3 \mathrm{~mm} . \mathrm{s}^{-1}$, track length was $5 \mathrm{~mm}$, and the total sliding distance was $10 \mathrm{~m}$. During the entire test, the friction force was recorded at a sampling rate of $800 \mathrm{~Hz}$ using a piezoelectric 
sensor placed below the stage on which the sample was mounted. To determine the wear rate, the worn samples were examined using a 3D non-contact optical profilometer (Zygo Corporation, USA). Wear track profiles, which were perpendicular to the sliding direction, were generated at different locations starting from one end of the wear track to the other. At least 35 profiles were generated, and the wear area was calculated by integrating the area above and below the reference surface (unworn coating). The wear area $\left(\mathrm{mm}^{2}\right)$ was then multiplied by the track length (mm) to obtain the wear volume $\left(\mathrm{mm}^{3}\right)$ and was subsequently normalized with sliding distance $(\mathrm{m})$ and normal load $(\mathrm{N})$ to obtain wear rate in $\mathrm{mm}^{3} \cdot \mathrm{N}^{-1} \cdot \mathrm{m}^{-1}$. At least 3 wear tests were done on each coating and at every condition to determine the average wear rate.

To understand the wear mechanisms, the worn surfaces and counterfaces were examined under SEM (SU3500, Hitachi, Japan). To identify the different phases formed during the wear process, Raman analysis was performed on the wear tracks and counterface using an inVia Raman spectrometer (Renishaw, UK) with $\mathrm{Ar}^{+}$laser source of $\lambda=514.5 \mathrm{~nm}$. To characterize the third bodies and subsurface microstructures, ECCI was performed on the polished wear track crosssections using FE-SEM SU8230 (Hitachi, Japan) equipped with a FlatQUAD EDS detector (Bruker, USA). In addition, EDS mapping was performed at $3 \mathrm{keV}$ and $8 \mathrm{keV}$ accelerating voltages to understand the elemental distribution in the tribolayers. The mechanical properties of the third bodies and the subsurface were determined by performing nanoindentation on the polished wear track cross-sections using a Triboindentor (Hysitron Corporation, USA). Indentation was performed using a Berkovich tip at a peak load of $5 \mathrm{mN}$ in a rectangular grid pattern starting from the unworn surface below the wear track up till the top surface. The hardness of the tribolayer and the subsurface was determined from the load-displacement curves using Oliver and Pharr method [29] and each hardness value represents an average of 10 indents. After indentation, the residual indents were imaged using an SEM and the corresponding indents were matched with the respective load-displacement curves to determine the hardness of a particular feature. To compare the subsurface microstructures below the tribolayers and the bare wear track, thin lamella were cut using focus ion beam (FIB) (FEI Helios Nanolab 660, Thermo Fisher Scientific, USA) and were examined under a cryo-transmission electron microscope (TEM) (FEI Tecnai G2 F20, Thermo Fisher Scientific, USA). 


\section{Results}

\subsection{Coating deposition}

BSE images of the MMC cross-sections along with the size distribution of the ceramic particles in the coatings are shown in Fig. 2. In the BSE images, the grey regions correspond to ceramic particles while the dark regions represent porosity. Most ceramic particles retain their spherical morphology with some evidence of fragmented particles (see Fig. 2). Table 1 summarizes the ceramic content in the initial feedstock, ceramic retained in the coating, porosity, MFP and hardness of the coatings deposited using spherical and irregular powders. From Table 1, the ceramic retention in the coatings was significantly lower than the initial feedstock mainly due to the rebound of the ceramic particles upon impact [18,30]. Coatings deposited using irregular powders showed higher ceramic retentions and lower porosity compared to spherical powder (SP) composite coatings at similar initial metal-ceramic mixtures. In all the coatings, MFP between the ceramic particles decreased with an increase in ceramic retention. At similar ceramic volume fractions (i.e. 15\% $\mathrm{TiC}$ and 16\% TiC), irregular powder (IP) deposited MMC showed lower MFP compared to SP deposited MMC. This could be due to the greater fragmentation of the ceramic particles in IP MMC compared to SP, as indicated by the particle size distribution histogram (see Fig. 2). Hardness increased with an increase in ceramic retention in the coatings. This was due to the presence of higher volume fraction of ceramic particles that increase the load bearing capacity of the coatings.

Table 1 Coating properties.

\begin{tabular}{cccccc}
\hline $\begin{array}{c}\text { Ti6AI4V } \\
\text { powder }\end{array}$ & $\begin{array}{c}\text { TiC vol.\% } \\
\text { (feedstock) }\end{array}$ & $\begin{array}{c}\text { TiC vol.\% } \\
(\text { retained) }\end{array}$ & $\begin{array}{c}\text { Porosity } \\
(\mathbf{\%})\end{array}$ & $\begin{array}{c}\text { MFP } \\
(\boldsymbol{\mu m})\end{array}$ & $\begin{array}{c}\text { Hardness } \\
\left(\mathbf{H V}_{\mathbf{5 g}}\right)\end{array}$ \\
\hline Spherical & 50 & $15.0 \pm 1.2$ & $5.0 \pm 0.7$ & 80 & $218 \pm 10$ \\
Irregular & 35 & $16.0 \pm 1.0$ & $1.1 \pm 0.4$ & 69 & $233 \pm 8$ \\
Irregular & 50 & $23.0 \pm 1.0$ & $1.0 \pm 0.4$ & 43 & $274 \pm 19$ \\
\hline
\end{tabular}



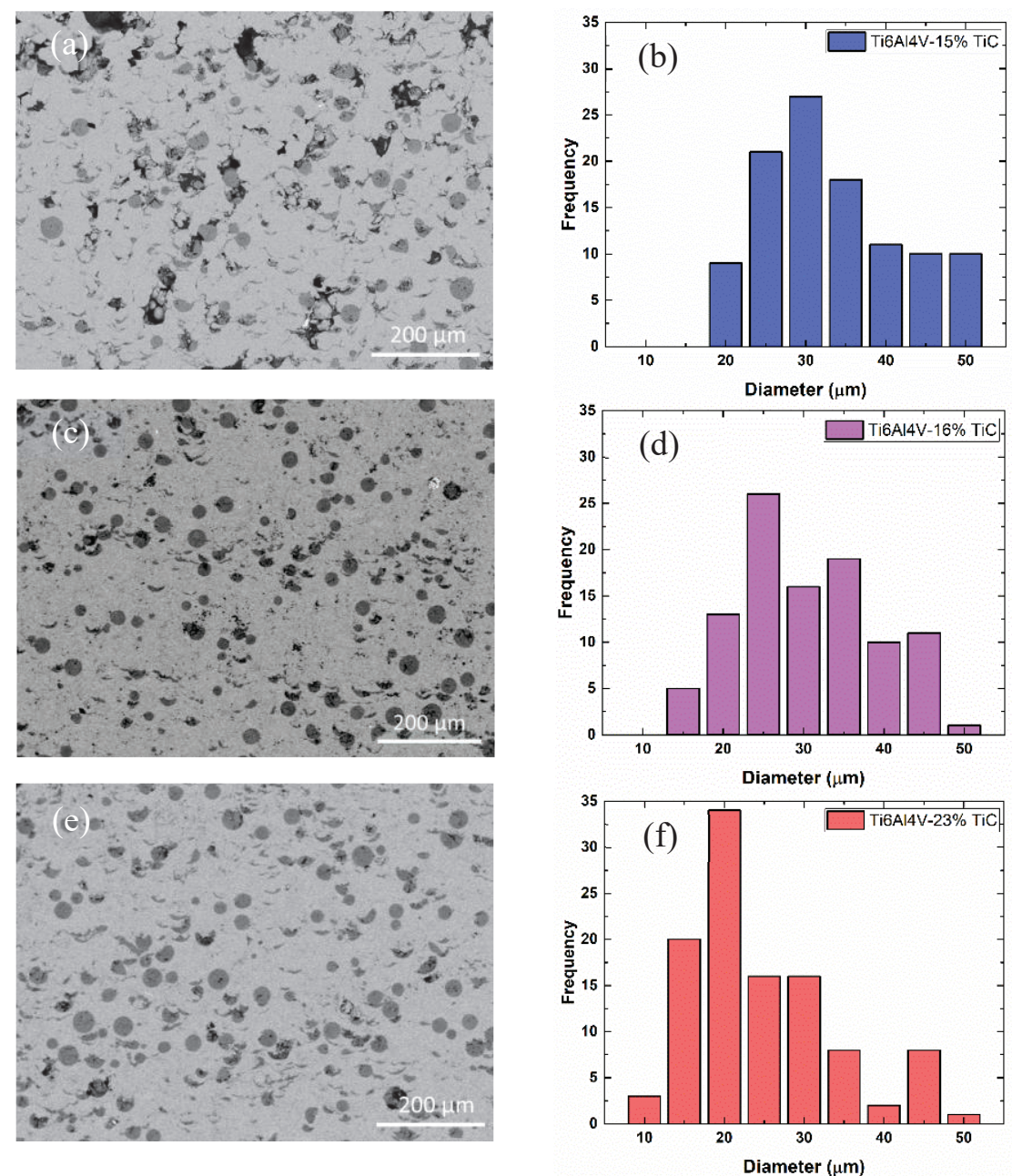

Fig. 2: Backscattered electron (BSE) images of the coating cross-sections of Ti6Al4V (a) $15 \% \mathrm{TiC}$ (SP) (c) $16 \% \mathrm{TiC}$ (IP) (e) $23 \% \mathrm{TiC}$ (IP); (b), (d) and (f) show the corresponding ceramic particle size distribution in the coatings.

\subsection{Friction and wear of the coatings}

The coefficient of friction $(\mathrm{CoF})$ vs cycle number is plotted for the coatings at both loads (shown in Fig. 3). SP composite coating showed highly fluctuating friction behaviour at both loads (Fig 3a). At $0.5 \mathrm{~N}$ normal load, the $\mathrm{CoF}$ was found to be fluctuating between $\sim 0.48-0.77$ whereas at $2.5 \mathrm{~N}$ it was between $\sim 0.33-0.53$. The average $\operatorname{CoF}(0-10 \mathrm{~m})$ was calculated to be $0.62 \pm 0.06$ at $0.5 \mathrm{~N}$ and $0.44 \pm 0.03$ at $2.5 \mathrm{~N}$. In contrast, IP composite coatings (both $16 \%$ and $23 \%$ ) at $0.5 \mathrm{~N}$ showed similar high $\mathrm{CoF}$ in the initial cycles and as the test progressed a significant drop in $\mathrm{CoF}$ was observed (Fig. 3b). In case of a composite coating with $16 \% \mathrm{TiC}$, high $\mathrm{CoF}$ of $\sim 0.55$ was seen up to 150 cycles followed by a drop to a steady state value of $0.30 \pm 0.01$. In $23 \% \mathrm{TiC}$ composite 
coatings, the high CoF of $\sim 0.56$ (average) was observed until 25 cycles, followed by a drop to a steady state value of $0.34 \pm 0.02$. Furthermore, CoF after the friction drop in both the coatings was found to be less fluctuating and henceforth did not show any subsequent rise. At $2.5 \mathrm{~N}$, IP composite coating with $16 \% \mathrm{TiC}$ exhibited largely fluctuating $\mathrm{CoF}$ with an average value of 0.45 \pm 0.04 which was similar to SP $15 \% \mathrm{TiC}$ coating. However, $23 \% \mathrm{TiC}$ coating at $2.5 \mathrm{~N}$, showed higher $\mathrm{CoF}$ of $\sim 0.42$ during the initial cycles, and as the test progressed the CoF dropped to a steady state value of $\sim 0.25$ after 140 cycles and henceforth remained low (Fig. 3b). In case of $23 \%$ TiC coatings, the steady state $\mathrm{CoF}$ at $2.5 \mathrm{~N}$ was found to be lower and less fluctuating compared to other composite coatings.
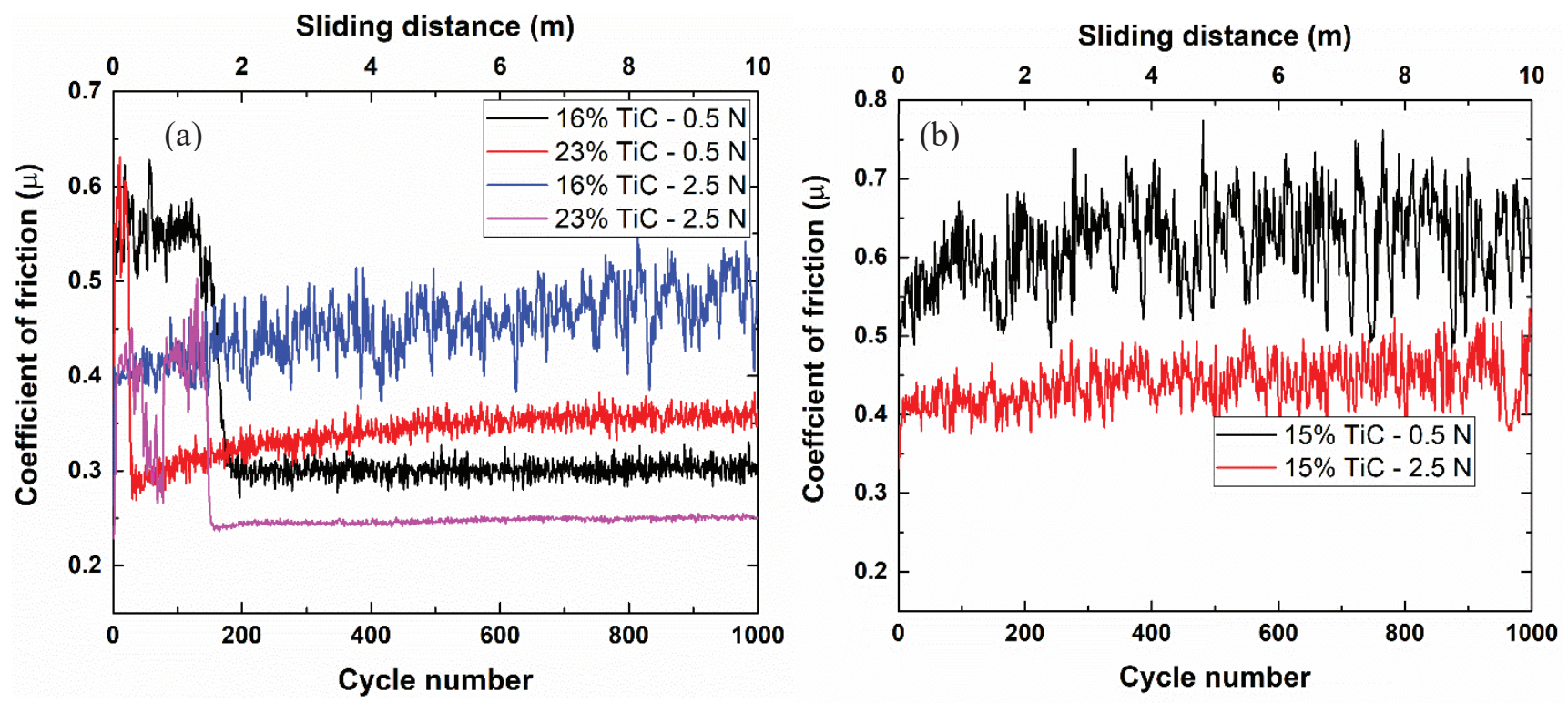

Fig. 3: CoF vs cycle number at respective loads (a) spherical and (b) irregular powder coatings. 
Wear rate calculated at the end of the test (i.e. $10 \mathrm{~m}$ ) for the coatings at both the loads is shown in Fig. 4. First, comparing the wear rates of spherical and irregular powder composite coatings with similar ceramic retentions i.e. 15\% TiC (SP) and 16\% TiC (IP), at both loads IP composite exhibited lower wear rates compared to SP composite. The difference in wear rates between the two coatings was greater at $0.5 \mathrm{~N}$ than at $2.5 \mathrm{~N}$ (see Fig. 4). Comparing the two IP deposited composites (16\% and $23 \% \mathrm{TiC})$, higher ceramic retention led to lower wear rates at both loads. Furthermore, composite coating with $23 \%$ TiC showed the lowest wear rate even at $2.5 \mathrm{~N}$ normal load. Increase in normal load led to a significant increase in wear rate in composite coating with $16 \% \mathrm{TiC}$, whereas, wear rate increased only marginally for the $23 \% \mathrm{TiC}$ composite coating (Fig. 4).

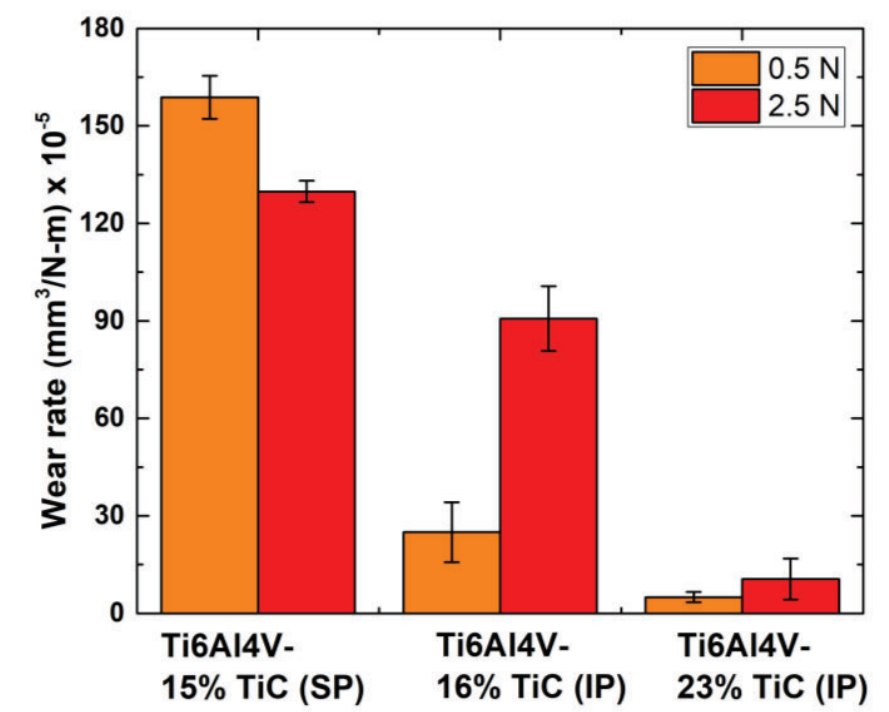

Fig. 4: Wear rate of the coatings calculated at the end of the test.

\subsection{Wear track morphology and phase analysis}

The SEM images of the wear tracks are shown in Figs. 5, 6 and 7. The worn surface of SP composite coating $(15 \% \mathrm{TiC})$ at $0.5 \mathrm{~N}$ and $2.5 \mathrm{~N}$ showed abrasive wear, with characteristics of ploughing by the wear debris and scoring by the counterface (Fig. 5a-c). Furthermore, at specific locations inside the wear track, evidence of splat delamination was observed (Fig. 5a-b). Worn surfaces of IP deposited composites showed different features on the wear tracks depending on the ceramic content and normal test load. At $0.5 \mathrm{~N}$, both $16 \% \mathrm{TiC}$ and $23 \% \mathrm{TiC}$ composite coatings showed the formation of islands of tribolayers on the wear track (Fig. 6a-c). The tribolayers on the 
wear track of $23 \%$ TiC coatings were found to be covering a higher area fraction compared to $16 \%$ TiC. BSE images of the wear track showed that these tribolayers were formed around TiC carbide particles (Fig. 6b) and appeared to be comprised of wear debris agglomerated and sintered together (Fig. 6b). EDS map of the tribolayers showed the presence of oxygen and carbon along with Ti at few specific locations indicating that these were oxides of Ti and fragmented TiC particles (Fig. 6d). At $2.5 \mathrm{~N}, 16 \% \mathrm{TiC}$ coating showed abrasive wear with no visual evidence of tribolayer formation in lower magnification SEM images (Fig. 7a). However, higher magnification images of the wear tracks showed the formation of tribolayers (Fig. 7b) but were significantly less compared to the wear track at $0.5 \mathrm{~N}$ (comparing Figs. 6a and 7a). In case of 23\% TiC coating, a more continuous tribolayer compared to any other worn surface was observed on the wear track as shown in Fig. 7c. However, the tribolayer did not cover the entire wear track but rather was found to be like a strip that extended from one end to the other end of the wear track.

Raman analysis performed on the Ti6Al4V and $\mathrm{TiC}$ particles in the unworn coating is shown in Fig. 8a. Raman spectra of wear debris showed characteristic peaks corresponding to rutile and anatase phases of $\mathrm{TiO}_{2}$ along with $\mathrm{TiC}$ (Fig. 8b). This indicated that the wear debris comprised of both oxides of $\mathrm{Ti}$ and fragmented carbide particles. Raman analysis on the tribolayers of IP composite coatings showed peaks corresponding to the rutile and anatase phases of $\mathrm{TiO}_{2}$ along with TiC (Fig. 8c). In addition, Raman peaks at $1326 \mathrm{~cm}^{-1}$ and $1556 \mathrm{~cm}^{-1}$ that corresponded to the $\mathrm{D}$ and $\mathrm{G}$ peaks of carbon were observed. These peaks were significantly broad compared to spectra obtained on the initial TiC particle (Fig. 8a). For both coatings, wear tracks regions away from tribolayers showed no active Raman peaks.
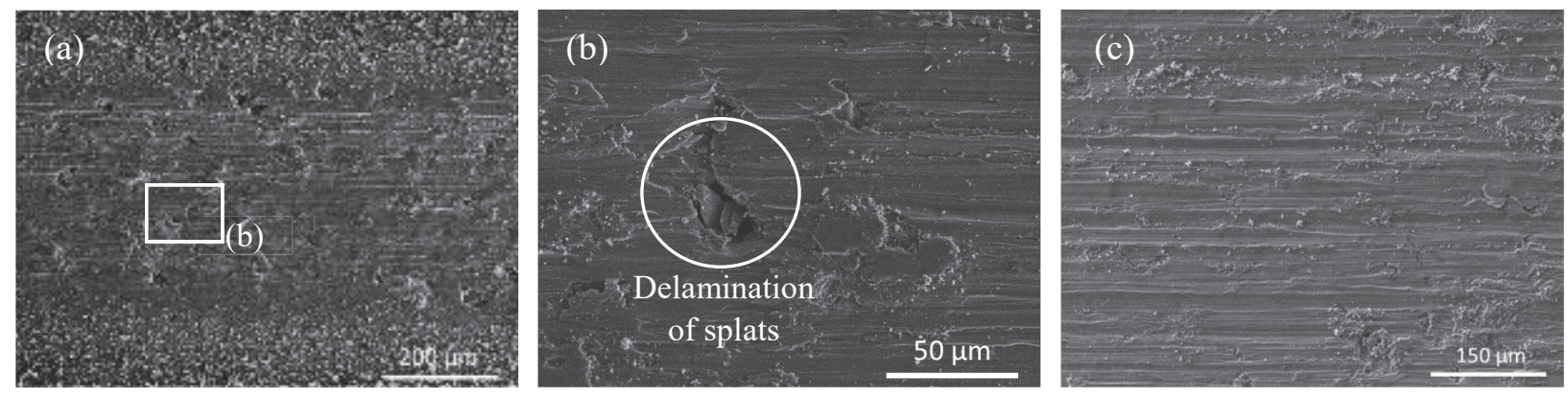

Fig. 5: Secondary electron (SE) images of the wear track of SP 15\% TiC MMC tested at normal load (a) $0.5 \mathrm{~N}$ (b) higher magnification image of the region shown in 'a', (c) $2.5 \mathrm{~N}$. 


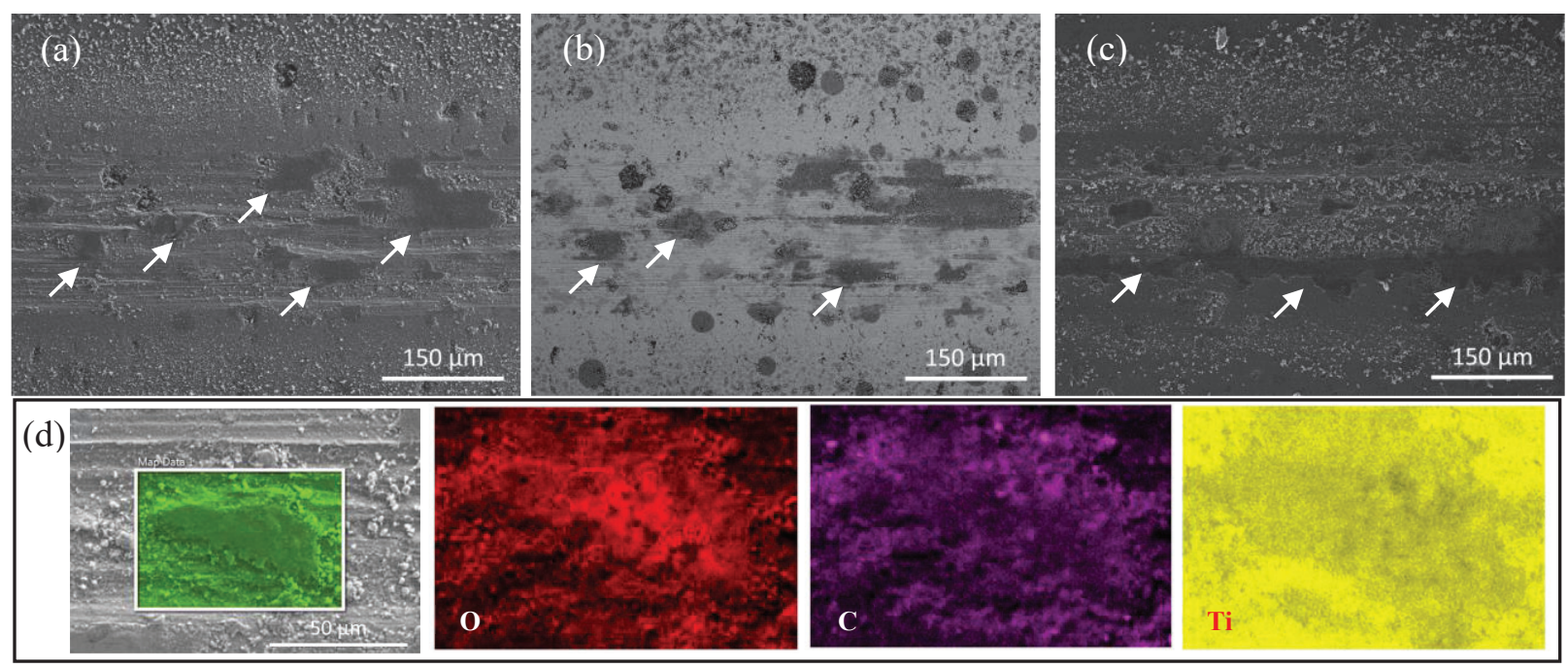

Fig. 6: Scanning electron microscope (SEM) images of the wear tracks of IP composites tested at normal load $0.5 \mathrm{~N}$ with (a) $16 \% \mathrm{TiC}$ (b) corresponding BSE image (c) $23 \% \mathrm{TiC}$ (d) EDS map of the tribolayer of $16 \% \mathrm{TiC}$ composite showing $\mathrm{O}, \mathrm{C}$ and Ti distributions; Arrows in the images show tribolayers.
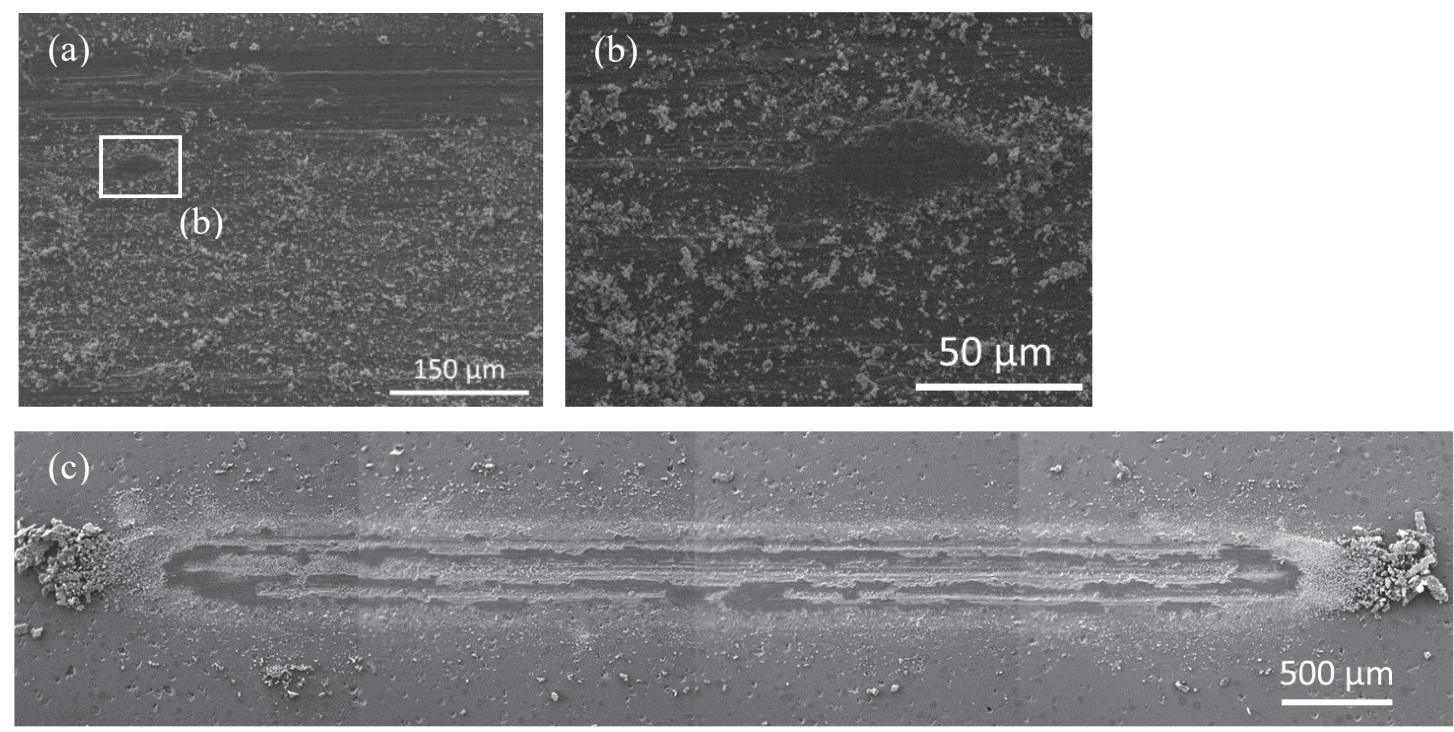

Fig. 7: SEM images of the wear tracks of IP composites tested at normal load $2.5 \mathrm{~N}$ with (a) $16 \% \mathrm{TiC}$ (b) higher magnification image of the region shown in (a); (c) $23 \%$ TiC showing more continuous tribolayer formation. 

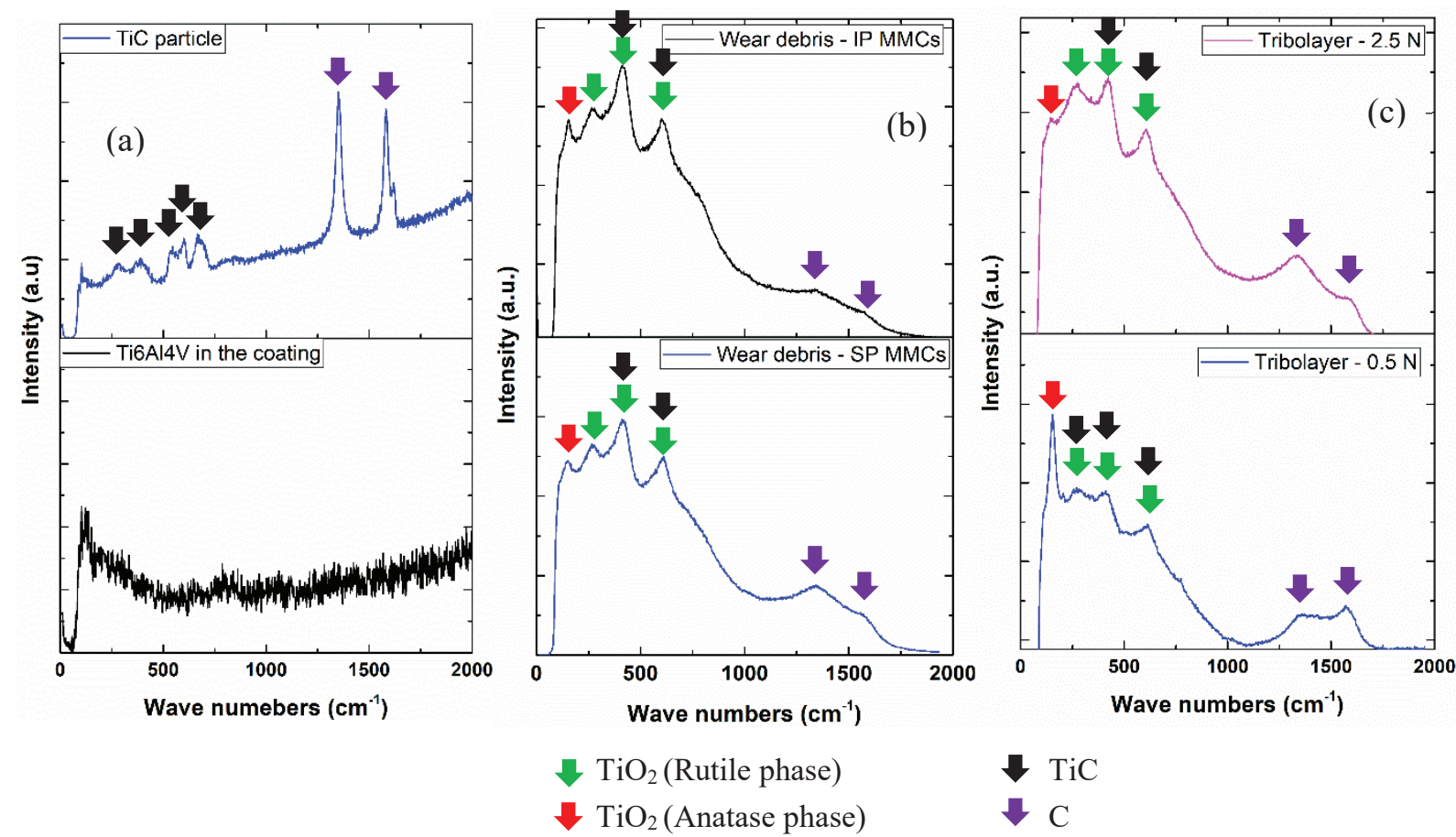

Fig. 8: Raman spectra of (a) Ti6Al4V and TiC particle in the coating (b) wear debris on the wear track of spherical and irregular powder composites at $2.5 \mathrm{~N}$ normal load (c) tribolayer formed at different normal loads.

\subsection{Counterface analysis}

SEM images of the counterface after the completion of the sliding tests at $2.5 \mathrm{~N}$ load are shown in Fig. 9. At $2.5 \mathrm{~N}$, all the counterfaces expect $23 \%$ TiC coating counterface, showed the presence of transfer film at the contact surface surrounded by wear debris (Fig. 9a and 9b). The formation of transfer film on the counterface during sliding wear of Ti and its alloys is due to its low d-bond character that facilitates for its high reactivity with other materials [2,31]. Raman analysis on the transfer film and wear debris showed characteristic Raman peaks corresponding to both $\mathrm{TiO}_{2}$ and TiC, indicating the presence of fragmented TiC particles in the transfer film (Fig. 10a). In case of $23 \% \mathrm{TiC}$ coatings at $2.5 \mathrm{~N}$, the counterface showed negligible evidence of adhesive transfer film at the contact surface (see Fig. 9c). Furthermore, at specific locations near the contact surface, smeared wear debris were observed along with small traces of a transfer film. A comparison of the distance between these smeared regions on the counterface, to the tribolayers on the wear track indicated that the real contact between the wear track and the counterface occurred at these specific locations. In addition, wear debris were found to be surrounding the contact surface similar to other 
counterfaces. Raman analysis on the wear debris and smeared regions showed peaks corresponding to the $\mathrm{TiO}_{2}$ and $\mathrm{TiC}$ (Fig. 10b) indicating the transfer of tribolayer material from the wear track on to the counterface. At $0.5 \mathrm{~N}$, the counterfaces of all the composite coatings showed the presence of adhesive transfer film (similar to $15 \%$ and $16 \% \mathrm{TiC}$ mated counterfaces at $2.5 \mathrm{~N}$ load) comprising of oxides of $\mathrm{Ti}$ and fragmented $\mathrm{TiC}$ particles (confirmed by Raman analysis) at the contact surface surrounded by wear debris (not shown here).


Fig. 9: SE images of counterfaces after the test at normal load $2.5 \mathrm{~N}$ mated with (a) $15 \% \mathrm{TiC}$ (b) $16 \% \mathrm{TiC}$ (c) $23 \% \mathrm{TiC}$ composite coatings.
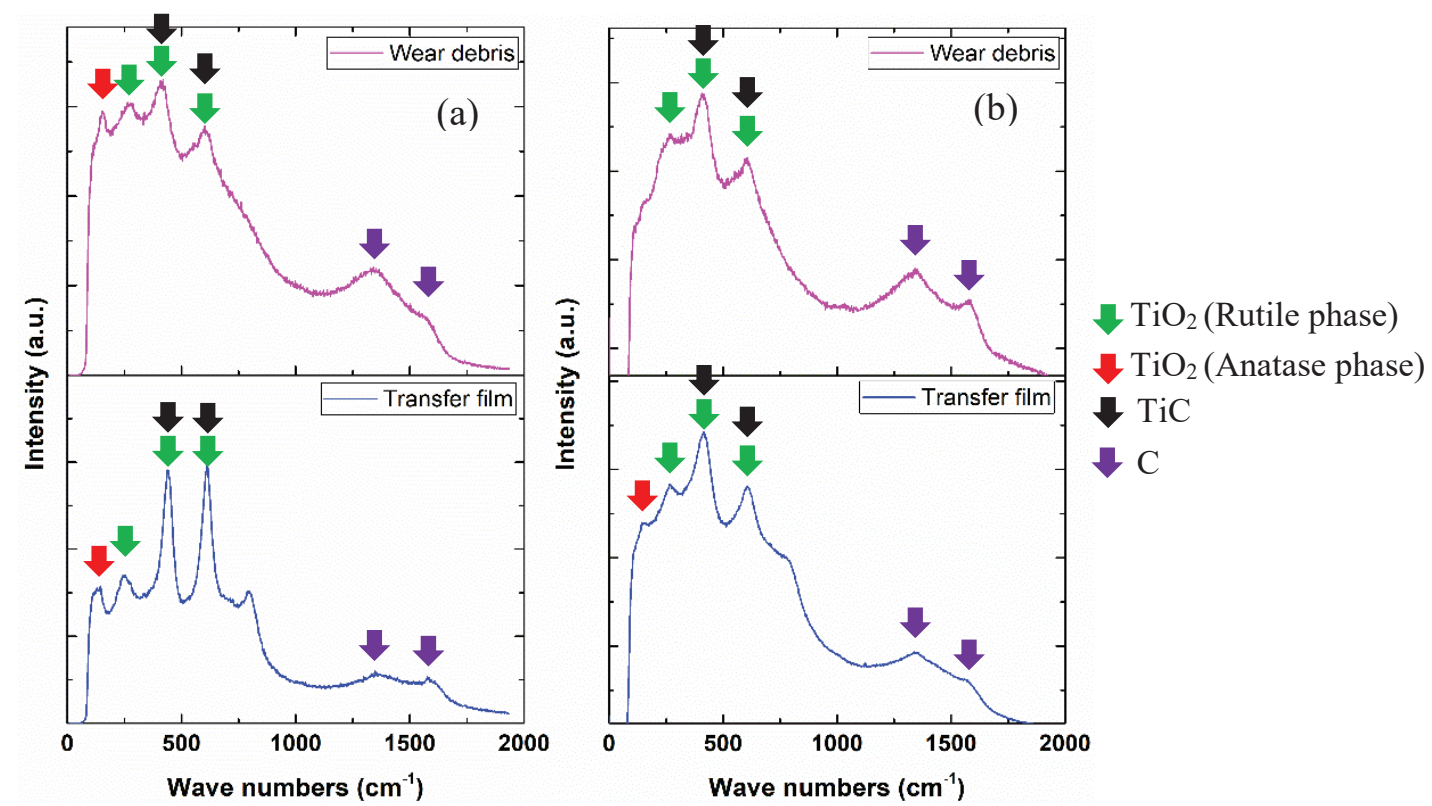

Fig. 10: Raman spectra of (a) transfer film and wear debris (surrounding the transfer film) formed on the counterface mating with 16\% TiC MMC (b) transfer film and wear debris (surrounding the transfer film) formed on the counterface mating with $23 \% \mathrm{TiC} \mathrm{MMC}$ at $2.5 \mathrm{~N}$. 


\subsection{Subsurface analysis of the wear tracks}

ECCI of the wear track cross-sections after the wear tests are shown in Fig. 11 and 12. At 2.5 N, wear track cross-sections of SP composite coatings did not show the presence of tribolayers (Fig. 11a) which coincided with the wear track SEM images. Below the wear track, formation of ultrafine grain (UFG) layer of thickness $\sim 3.5 \mu \mathrm{m}$ was observed (Fig. 11b). Underneath the UFG layer, a mixture of UFGs and fine grains (FGs) (Fig. 11c) and finally the martensitic lath microstructure (initial microstructure) (see Fig. 11d) was observed. The average grain size in the UFG region was $\sim 70 \pm 20 \mathrm{~nm}$. Similarly, at $0.5 \mathrm{~N}$, UFGs of size $\sim 90 \pm 20 \mathrm{~nm}$ were observed up to a distance of $\sim 5.2 \mu \mathrm{m}$ (below the wear track) and beneath the UFG layer, FGs and martensitic laths (not shown here) were seen. In case of IP deposited 16\% TiC composite coating, at $2.5 \mathrm{~N}$, tribolayer of thickness $\sim 1.6 \mu \mathrm{m}$ was observed as shown in Fig. 11e. EDS map of the tribolayer clearly showed the presence of fragments of TiC particles embedded in the tribolayer along with oxygen and titanium rich regions (see Fig. 11j). The regions in the tribolayer with bright contrast had high amount of Ti while the dark regions were rich in oxygen. Underneath the tribolayer, an $\sim 2.7 \mu \mathrm{m}$ thick layer of UFGs (see Fig. 11f-g) of average size $\sim 80 \pm 30 \mathrm{~nm}$ were seen. Below UFGs, a region comprising of highly deformed microstructures (Fig. 11f and h) and underneath the deformed region, the coating initial microstructure (Fig. 11i) was observed. Similarly, at 0.5 $\mathrm{N}$, a thick tribolayer of $\sim 1.1 \mu \mathrm{m}$ with a UFG layer of thickness $\sim 3.6 \mu \mathrm{m}$ underneath, and highly deformed and coarse grain microstructures below the UFG layer were observed (not shown here). The UFGs has an average grain size of $\sim 108 \pm 36 \mathrm{~nm}$. In case of $23 \% \mathrm{TiC}$ composite coating at 2.5 N, tribolayer of thickness $\sim 1.1 \mu \mathrm{m}$, and UFGs of size $\sim 100 \pm 30 \mathrm{~nm}$ beneath the tribolayer were observed as shown in Fig. 12a-c. The UFG region had a thickness of $\sim 2 \mu \mathrm{m}$ (see Fig. 12b) and underneath this region, the microstructure was found to be highly deformed. Similarly, at 0.5 $\mathrm{N}$, tribolayer comprising of $\mathrm{TiC}$ fragments embedded into fine agglomerated $\mathrm{TiO}_{2}$ wear debris was observed (see Fig. 12d). The tribolayer had a thickness of $\sim 2.4 \mu \mathrm{m}$ (Fig. 12d) and underneath the tribolayer, a layer of UFGs of size $\sim 110 \pm 50 \mathrm{~nm}$ (Fig. 12e) was seen. Below the UFG layer (thickness $\sim 2 \mu \mathrm{m}$ ), a mixture of coarse grain and highly deformed microstructures that extended into the coating until the initial microstructure was observed (as shown in Fig. 12f). 

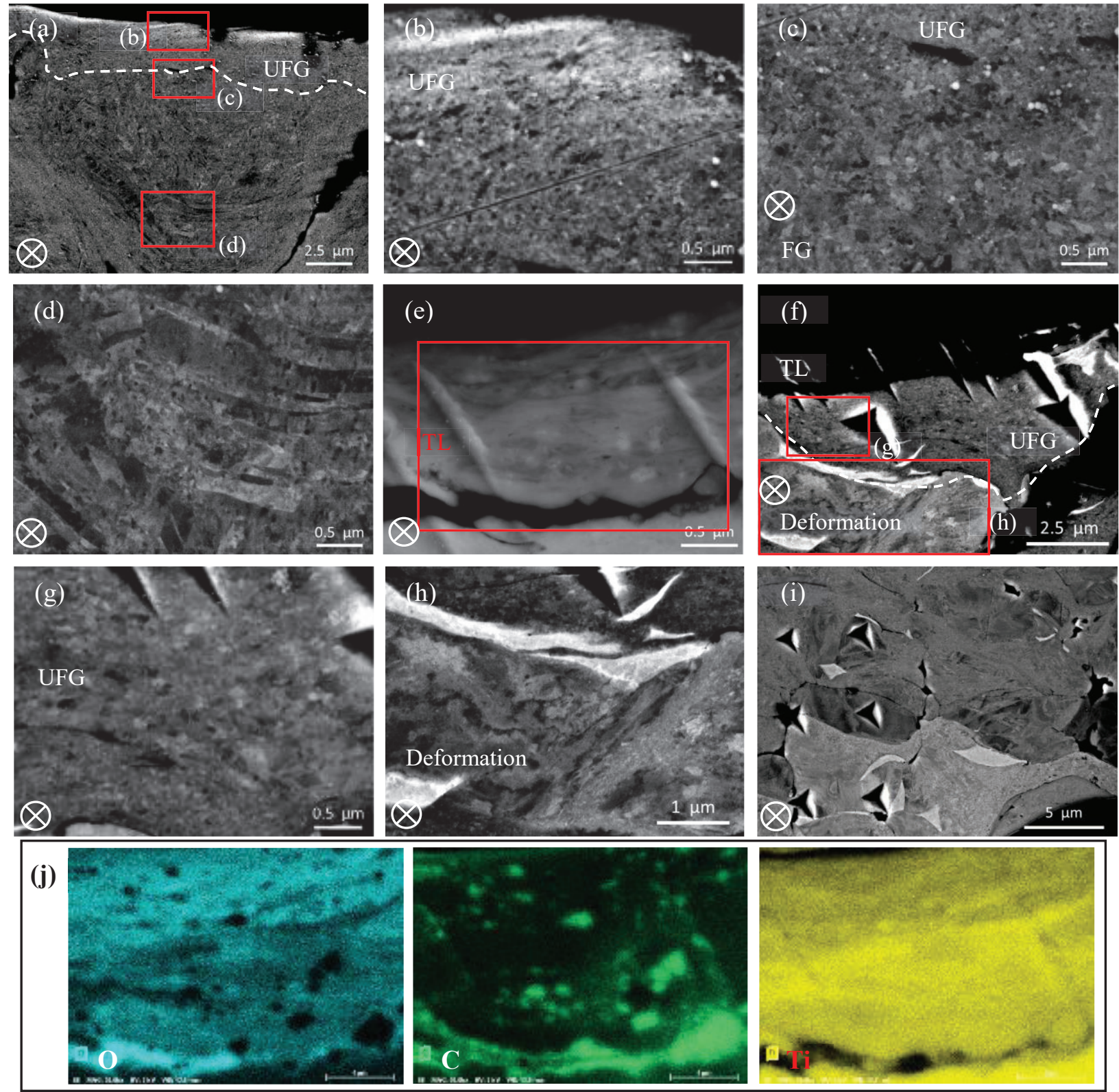

Fig. 11: ECCI of the wear track cross sections tested at $2.5 \mathrm{~N}$ normal load corresponding to spherical powder $15 \%$ TiC coatings (a) worn subsurface (b) near surface region showing UFGs (c) subsurface showing UFG and FG (d) initial coating microstructure; Irregular powder 16\% TiC coatings - (e) tribolayer (TL) (f) region below the tribolayer (g) higher magnification image corresponding to location shown in ' $f$ ' showing UFG (h) higher magnification image corresponding to region shown in ' $\mathbf{f}$ ' showing deformed microstructures (i) initial coating microstructure (j) EDS map of the tribolayer (region shown by red box in 'e') showing O, C and Ti distributions. $\otimes$-indicates sliding direction. 



Fig. 12: ECCI of the wear track cross sections of Ti6Al4V-23\% TiC coating tested at (a) $2.5 \mathrm{~N}$ showing tribolayer (TL) (b) $2.5 \mathrm{~N}$ - lower magnification image showing regions below tribolayer (c) $2.5 \mathrm{~N}$ - higher magnification image of the UFG region. (d) $0.5 \mathrm{~N}$ - showing the tribolayer (e) $0.5 \mathrm{~N}$ - region below the tribolayer (f) $0.5 \mathrm{~N}$ - lower magnification image showing UFGs with highly deformed microstructures beneath; $\bigotimes$ - indicates sliding direction.

Figure 13 shows the TEM images of the worn cross-section of Ti6Al4V-23\% TiC composite coating (tested at $2.5 \mathrm{~N}$ normal load) and the specific location of the FIB cut on the wear track (Fig. 13a). From the TEM image, the tribolayer thickness was found to be $\sim 1.05 \pm 0.2 \mu \mathrm{m}$ and cracks were observed underneath the tribolayer (see Fig. 13b). Furthermore, the tribolayer was found to be an agglomeration of compacted fine wear debris as seen from their bright field and dark field images respectively (Fig. 13c). These features were similar to those observed in the ECCI of the worn cross-sections. Selected area electron diffraction (SAED) pattern of the tribolayer showed ring pattern indicating that they had a nanocrystalline structure (see Fig. 13d). The d-spacing calculated from the SAED pattern matched well with that of rutile and anatase phases of $\mathrm{TiO}_{2}$, indicating that the nanocrystalline tribolayer comprised of oxides of $\mathrm{Ti}$. Underneath the tribolayers, elongated and highly deformed grains along with few UFGs were observed (Fig. 13e) while regions away from the tribolayer showed mostly ultrafine grains (Fig. $13 \mathrm{~g})$. The coarse grain structure underneath tribolayers was further confirmed by the discontinuous rings in the SAED (Fig. 13f) whereas region away from the wear track showed more continuous ring patterns indicating the grains were nanocrystalline to corresponding $\alpha$-Ti (Fig. 13h). 

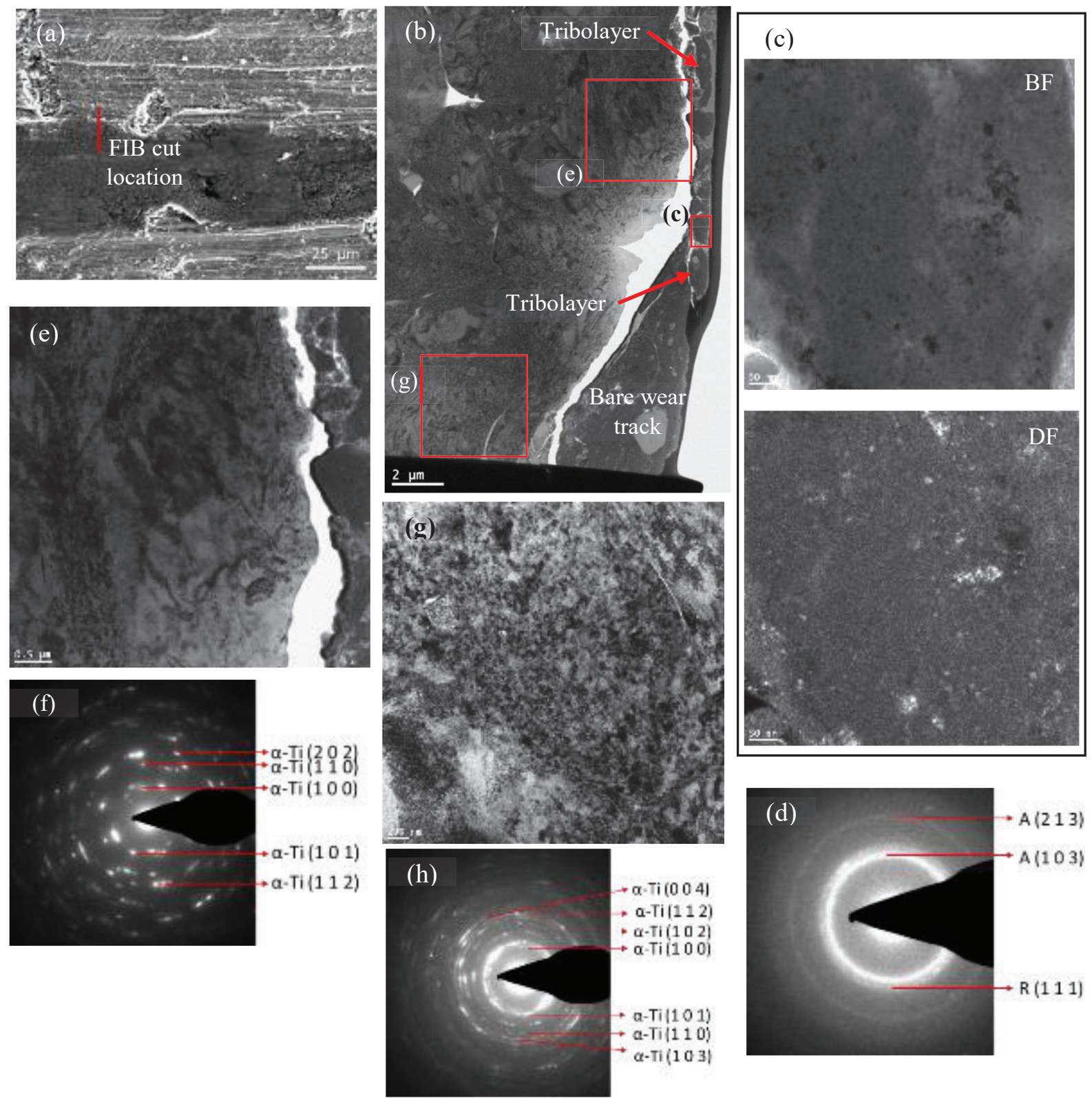

Fig. 13: Worn cross-section of Ti6Al4V-23\% TiC composite (a) location of FIB cut on the wear track; (b) TEM image of the subsurface cross-section (c) BF and DF image of tribolayer (d) SAED pattern of the tribolayer (e) higher magnification image of the region below the tribolayer (f) SAED pattern of the region below the tribolayer (g) higher magnification image of the region away from tribolayer (h) SAED pattern of the region away from the tribolayer; Red box in image ' $\mathbf{b}$ ' shows the location where the higher magnification images were taken; A- Anatase and $\mathrm{R}$ - Rutile phases of $\mathrm{TiO}_{2}$. 
Nanoindentation was performed to determine the hardness as a function of depth below the worn surface and is shown in Fig. 14. In case of SP composite coatings, the near surface hardness (corresponding to point zero on the X-axis) represents the hardness of UFG region (Fig. 14a) whereas in case of IP coatings it corresponds to the hardness of tribolayers (refer Fig. 14b). Comparing Figs. 14a and b, IP composite coatings showed higher near surface hardness compared to SP composite coatings at both loads due to the formation of tribolayers comprising of oxides of Ti along with fragmented TiC particles. In all the coatings, there was a trend of decrease in hardness with an increase in distance from the worn surface. However, this trend was more clearly seen in IP composite coatings.
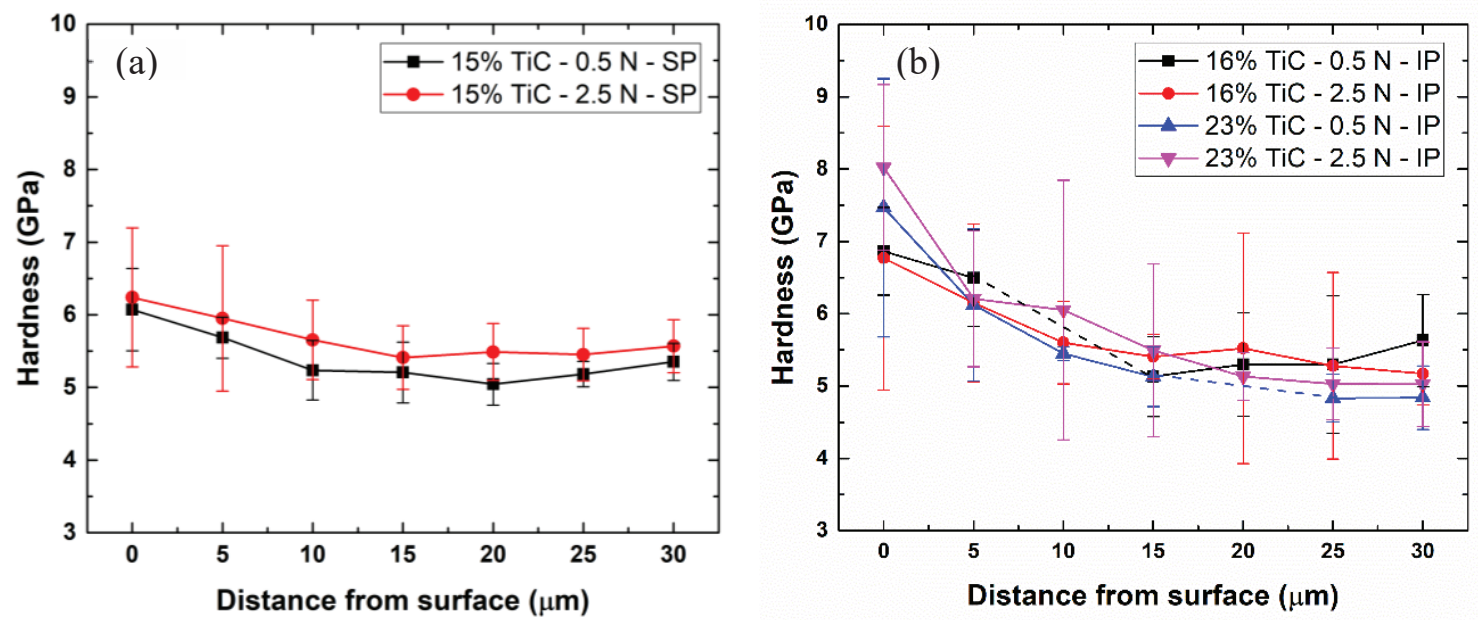

Fig. 14: Hardness profile of the worn cross-sections of (a) spherical and (b) irregular powder composite coatings tested at respective normal loads.

\section{Discussion}

\section{Tribology}

MMCs generally out-perform pure metals and alloys for their tribological performance for a few important reasons. These are discussed here in general in the context of source flows from the MMC, which can be from the metal, ceramic, or tribolayers (see Fig. 15). It should be noted that the reality of third bodies in a tribological contact $[32,33]$ are more complicated than simply source flows. However, to better understand and correlate the changes in friction and wear behaviour, 
observed microstructural features on the worn surfaces in the present study, to third bodies concept, this discussion is more focussed in terms of source flows.

In the literature, a common reason for improved tribological performance for MMCs is that ceramic particles, with their higher stiffness and strength, provide "load support". Better mechanical properties themselves may help to reduce wear, but they will also reduce the contact area for a tribological couple. This, in turn, will reduce the number of frictional junctions and potentially reduce the source flow in the early stages of sliding. However, as sliding commences, there will inevitably be wear and this most often initially occurs as metallic source flow, $\mathrm{Q}_{\mathrm{sm}}$ (as shown in Fig 15a) [2,34,35]. For this reason, having an increased quantity of ceramic is desirable as it will reduce the fraction of the surface that is exposed metallic matrix and thus the initial metallic source flow, $\mathrm{Q}_{\mathrm{sm}}$. Initial source flow of the ceramic, $\mathrm{Q}_{\mathrm{sc}}$, is often very small unless the composite is poorly engineered with very low cohesive strength. A second common reason for good tribological performance for MMCs is that ceramic particles tend to enhance the formation of tribolayers on the surface $[6,27,35]$, an important mechanism to reduce wear at longer sliding distances (see Fig 15b). The tribolayers may be in the form of tribo-oxides, sometimes called glaze layers, or simply mechanically mixed layers (MMLs). Depending on the composition of the tribolayer and its cohesion, it may impart a moderate to significant reduction in friction and/or wear. In general, though their formation and stability will inherently act to reduce source flow from both the matrix and the reinforcement by minimizing exposure of the parent material to the sliding contact. The stability of tribolayers depends partly on having load-supporting material underneath. For this reason, both increased ceramic content and a matrix of higher strength is desired, which would help to reduce the source flow from tribolayers, $\mathrm{Q}_{\text {st. }}$ When the MMC is made by CS or other powder consolidation techniques, an additional important consideration is the cohesion strength of the matrix material. 


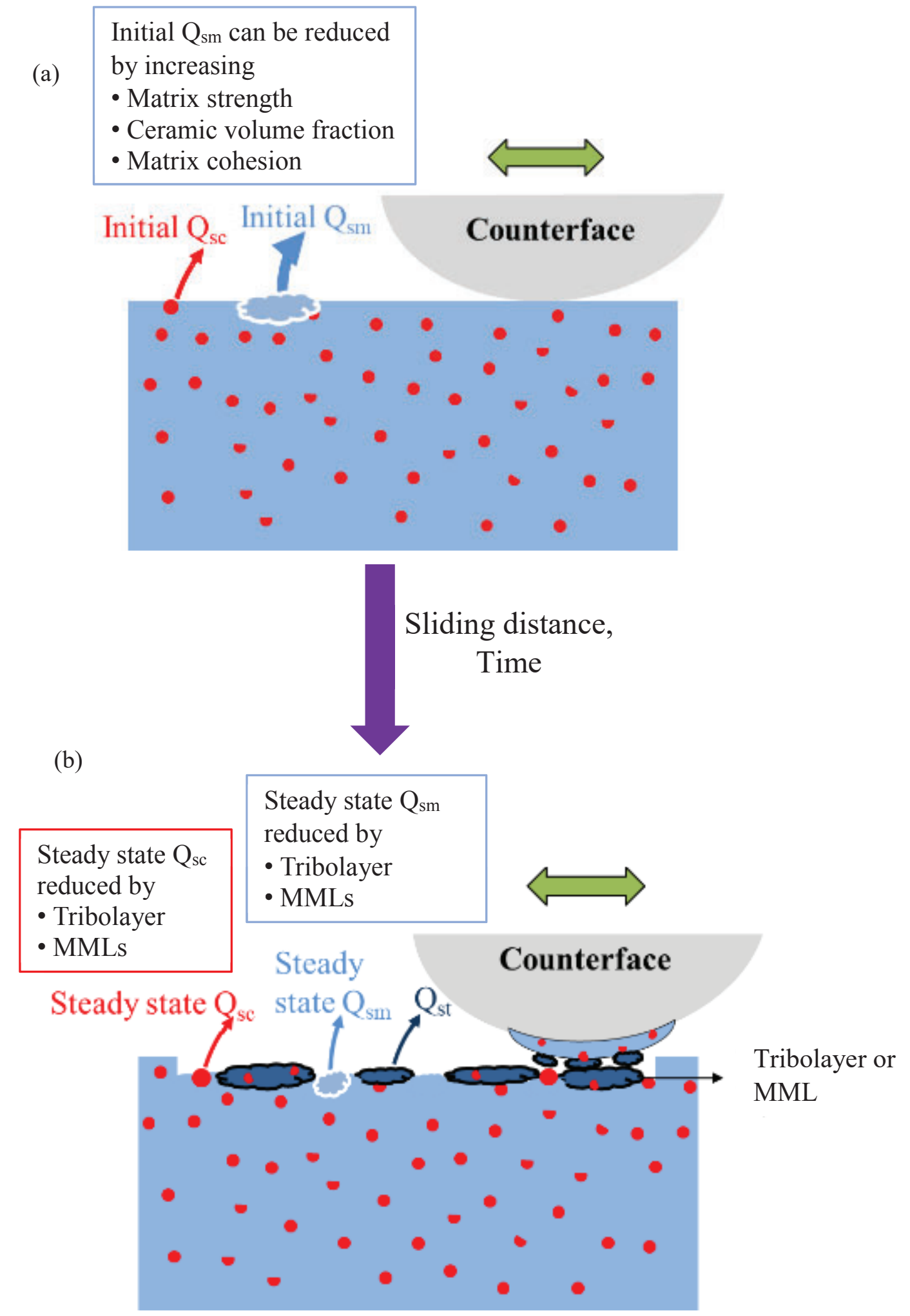

Fig. 15: Schematic showing source flows from a metal matrix composite at (a) early cycles (b) longer cycles. $\mathrm{Q}_{\mathrm{sm}}-$ Metallic source flow; $\mathrm{Q}_{\mathrm{sc}}-$ Ceramic source flow; $\mathrm{Q}_{\mathrm{st}}-$ Tribolayer source flow. Thickness of arrows indicate the amount of flow. MML - Mechanically mixed layer. 


\section{Ti6Al4V-TiC MMC Tribology}

In the present study, Ti6Al4V-TiC MMCs with different metal-ceramic mixtures were cold sprayed using two different metal powders, and their tribology was evaluated by performing reciprocating sliding wear tests. Ceramic volume fraction and matrix cohesion had a significant influence on the tribological performance of the Ti6Al4V-TiC MMCs. At lower normal load (i.e. $0.5 \mathrm{~N}$ ), during initial cycles, both spherical and irregular powder MMCs with similar ceramic contents (i.e. 15\% and 16\%) showed high CoF along with large fluctuations. In situ tribometry studies on cold sprayed Ti-TiC, $\mathrm{Al}-\mathrm{Al}_{2} \mathrm{O}_{3}$ MMCs [2,34] showed that friction fluctuations are often correlated to high source flows leading to dynamic third body activity i.e. plastic deformation, transfer of material to the counterface, and formation of wear debris. In case of SP MMC, CoF remained high and fluctuating throughout the test (see Fig. 3). The low hardness and poor cohesion between the particles in SP MMC would have facilitated source flow from the matrix, $\mathrm{Q}_{\text {sm, and }}$ the ceramic, $\mathrm{Q}_{\mathrm{sc}}$, resulting in high wear rates (Fig. 4). It is well known that Ti6Al4V coatings deposited from plasma processed powders often suffer from poor cohesive strength between the splats due to limited deformability of the particles [14,36,37]. Additionally, the presence of TiC particles could have further hampered the inter-splat bonding resulting in delamination during sliding. SEM images of the worn surfaces of SP MMC showed evidence of abrasion by the wear debris, which were mostly fragmented $\mathrm{TiC}\left(\right.$ from $\mathrm{Q}_{\mathrm{sc}}$ ) and $\mathrm{TiO}_{2}$ particles (from oxidized $\mathrm{Q}_{\mathrm{sm}}$ ) (Fig. 5a). These abrasive plough marks were similar to that of unreinforced Ti6Al4V coatings as reported in our previous study and literature [38-40]. Tribolayers for Ti and its alloys are known for their poor resistance to plastic shearing generally resulting in high wear rates [38,39,41-43]. The appearance of the wear tracks, with their absence of tribolayers and abrasive plow marks, indicates that reinforcement of $\mathrm{TiC}$ particles in SP deposited Ti6A14V matrix did not significantly influence the wear mechanisms and that the MMC had showed tribology mostly like that of an unreinforced Ti6Al4V coating.

In case of IP Ti6A14V-16\% TiC MMCs, the friction was fluctuating during early sliding times but

dropped to a lower friction value after 150 cycles (see Fig. 3). The lower MFP between the TiC particles and better matrix cohesive strength, reduced the initial source flow, $\mathrm{Q}_{\text {sm, }}$ and also provided better load support for tribolayers, leading to better stability and lower tribolayer source flow, $Q_{\text {st. }}$ In terms of CS, higher particle velocities and deformable microstructure of the irregular 
powders led to dense deposits with better inter-splat bonding compared to SP deposited coatings [14]. This prevented the delamination of splats during reciprocating sliding, another mechanism that would reduce metallic source flow, $\mathrm{Q}_{\mathrm{sm}}$, in IP composite. Tribolayers on the wear track were found to be formed mostly around the $\mathrm{TiC}$, which could be due to the strain localization around these particles. Furthermore, these tribolayers were an agglomeration of highly deformed wear debris and Raman analysis indicated the presence of glassy carbon in addition to $\mathrm{TiO}_{2}$ and $\mathrm{TiC}$ particles. The presence of free carbon in the tribolayers provided easy shear for counterface resulting in a low and less fluctuating $\mathrm{CoF}$ (after the drop). A further increase in ceramic content in IP coatings from 16\% to 23\%, decreased the MFP between the TiC particles and also increased the coating hardness. This would have resulted in a much lower source flow, $\mathrm{Q}_{\text {sm }}$, during the initial cycles in $23 \% \mathrm{TiC}$ MMC compared to $16 \% \mathrm{TiC}$. The greater coverage of the wear track with tribolayers for 23\% TiC MMC (see Fig. 6c) showed their stability that would have decreased steady state source flows significantly (as shown in Fig. 15b).

At higher normal load (i.e. $2.5 \mathrm{~N}$ ), the tribology of the MMCs was found to be largely dependent on the ceramic content rather than on the coating mechanical properties. At $2.5 \mathrm{~N}$, both SP and IP MMCs with 15\% and 16\% TiC respectively, showed high CoF and wear rates which was similar to Ti6A14V coatings, tested at similar conditions in our previous work [40]. Furthermore, SEM images of the wear track of SP 15\% TiC MMC (Fig. 5c) did not show any tribolayer formation, whereas minor evidence of tribolayers were observed in IP 16\% TiC MMC (Fig. 7b). The absence of significant amount of tribolayers might have led to continuous third bodies activities and abrasion in both coatings similar to unreinforced Ti6Al4V [40]. However, the wear rate of IP 16\% TiC MMC at $2.5 \mathrm{~N}$ was slightly lower compared to unreinforced IP Ti6A14V which could be due to its higher hardness. An increase in normal load from $0.5 \mathrm{~N}$ to $2.5 \mathrm{~N}$ resulted in marginal decrease in wear rate and average $\mathrm{CoF}$ for SP 15\% MMC. This could be due to tribo-oxidation similar to unreinforced SP Ti6Al4V coatings [40]. On the other hand, in 16\% TiC MMC at $0.5 \mathrm{~N}$, tribolayer formation led to a low CoF and wear rates, whereas at $2.5 \mathrm{~N}$, the absence of significant coverage of wear track area with tribolayers resulted in high friction and wear rate. This indicated that the reinforced ceramic volume fraction was not sufficient enough for the formation of protective tribolayers at higher loads, and high metal, $\mathrm{Q}_{\text {sm }}$, and ceramic, $\mathrm{Q}_{\mathrm{sc}}$, source flows might have been persistent over the entire test duration. On the other hand, IP MMC with 23\% TiC showed tribolayer formation even at higher normal loads. Specifically at $2.5 \mathrm{~N}$, these tribolayers were 
found to be highly continuous compared to lower loads resulting in very low average CoF of $\sim 0.25$ (after friction drop) along with low wear rate (Fig. 3b and 7c). During wear of MMCs (hard particle reinforced), the exposure of the reinforcing phase to the sliding interface facilitates for the formation of tribolayers that could significantly improve the tribology of the material compared to unreinforced metals or alloys $[6,7,27,44]$. In case of Ti6Al4V-23\% TiC MMC, higher ceramic volume fraction, lower MFP, and better cohesion (compared to $15 \%-16 \%$ TiC MMC) between the particles would have resisted the localized shear deformation of the coating and supported for the formation and stability of the tribolayers. It was further observed that the tribolayer had formed a strip over the entire wear track which enabled the counterface to slide on the tribolayer and have minimal interaction with the coating underneath (Fig. 7c). This would have resulted in negligible steady state source flows from the parent material (both $\mathrm{Q}_{\mathrm{sm}}$ and $\mathrm{Q}_{\mathrm{sc}}$ ) leading to a low wear rate along with lower fluctuations in $\mathrm{CoF}$ (after the friction drop) compared to other coatings and test conditions.

The formation of tribolayers on the wear tracks also affected the subsurface microstructure. Grains underneath the wear tracks were finer compared to the grains formed under the tribolayers, indicating greater stress transfer to the subsurface due to the absence of tribolayers (Fig. 13e and g). While the formation of tribolayers might have largely contributed to lower stress transfer due to their high hardness, it is also reported that the presence of friction between sliding surfaces changes the stress field at the contact interface [45-47]. During sliding in addition to the compressive normal stress due to normal load, presence of friction induces two additional stresses at the contact surface. First, it induces shear stress in the sliding direction, and second, a normal stress, that changes from compressive at the initial contact region of the counterface to tensile at the end of the contact $[46,47]$. The magnitude of these stresses are proportional to the CoF i.e. a lower CoF between the sliding surfaces will lead to lower stresses at the contact interface. In the present study, the formation of lubricating tribolayers on the wear tracks of IP coatings would have resulted in lower near-surface and subsurface stresses compared to wear tracks without tribolayers. This could have led to lower grain refinement below the tribolayers compared to the wear tracks without tribolayers. Thus, the formation of hard and lubricating tribofilms on the wear track decreased the $\mathrm{CoF}$, wear rate and also led to lower subsurface stresses resulting in an overall improvement in the tribology of MMCs. While the wear tests performed here were aimed to evaluate the tribological performance of cold sprayed Ti6A14V-TiC MMCs, longer duration tests 
at different normal loads that replicate the actual service conditions are necessary to explore the possibility of using these coatings for real engineering applications.

\section{Comparisons to Ti-TiC MMC Tribology}

To better understand cold sprayed MMC with a high strength material such as Ti6A14V as matrix for tribological applications, a comparison between the wear rates of Ti-TiC MMCs from literature [2] and Ti6Al4V-TiC MMCs from our present work, is shown in Fig. 16. Both samples are made using CS, where the metal powders are all plasma atomized with spherical morphology and the TiC is the same stock of plasma atomized powder. The specimens were also tested on the same tribometer with the same normal load of $0.5 \mathrm{~N}$ and ambient conditions. From Fig. 16, it can be seen that at similar $\mathrm{TiC}$ contents (i.e. $13.8 \%$ for $\mathrm{Ti}-\mathrm{TiC}$ and $15 \%$ for $\mathrm{Ti} 6 \mathrm{Al} 14 \mathrm{~V}-\mathrm{TiC}$ ), the wear rate of Ti-TiC was lower compared to SP Ti6Al4V-TiC. From SEM observation of coating crosssections, Ti-TiC MMCs were highly dense [2] whereas SP Ti6Al4V-TiC coatings had porosity. Table 2 summarizes the ceramic content and mechanical properties of Ti-TiC and Ti6Al4V-TiC MMCs from the present study and literature [2,14,36]. Ti6Al4V coatings deposited from plasma gas atomized powders are often porous and show poor cohesive strength due to limited deformability of the particles [14,36,37], which is an effect lessened when spraying more deformable Ti powder. In the current work, Ti6Al4V-TiC showed delamination of particles, leading to high initial source flows, $\mathrm{Q}_{\mathrm{sm}}$ and $\mathrm{Q}_{\mathrm{sc}}$, and abrasion from wear debris during sliding resulting in high friction and wear rates. On the other hand, the low porosity and better cohesion between the particles of Ti-TiC composite compared to SP Ti6Al4V-TiC (Table 2), would have provided better resistance to the excessive metallic source flow, $\mathrm{Q}_{\mathrm{sm}}$, during the initial cycles and facilitated for the formation of protective tribolayers [2]. Similar to Ti-TiC, IP Ti6Al4V-TiC MMC also had better bonding between the particles compared to SP Ti6Al4V-TiC (refer Table 2) due to better deformability and higher particle velocities of the irregular Ti6Al4V particles during deposition $[14,48]$. This would have led to better load bearing capacity, lower initial source flows $\mathrm{Q}_{\mathrm{sm}}$ and $\mathrm{Q}_{\mathrm{sc}}$, and facilitated for tribolayer formation on the worn surfaces resulting in low wear rates. However, the wear rate of IP 16\% TiC composite was lower compared to $\mathrm{Ti}-13.8 \% \mathrm{TiC}$ MMC (Fig. 16) which could be due to the slightly higher volume fraction of the TiC particles or better load bearing capacity of the alloy matrix. 
Table 2. Coating properties of Ti-TiC [2,36], Ti6Al4V-TiC (SP) and Ti6Al4V-TiC (IP) coatings [14]. In the Table, '+' indicated higher, '-' indicates lower, ' 0 ' indicates neutral or baseline.

\begin{tabular}{|c|c|c|c|}
\hline Coating & 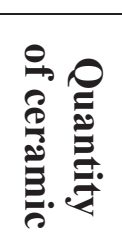 &  & 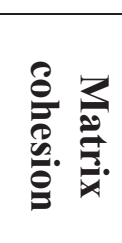 \\
\hline $\mathrm{Ti}-13.8 \% \mathrm{TiC}$ & + & 0 & ++ \\
\hline $\mathrm{Ti}-33.4 \% \mathrm{TiC}$ & +++ & 0 & ++ \\
\hline (SP) Ti6Al4V-15\% TiC & + & + & - \\
\hline (IP) Ti6Al4V-16\% TiC & + & + & + \\
\hline (IP) Ti6Al4V-23\% TiC & ++ & + & + \\
\hline
\end{tabular}

Comparing the wear rate of IP Ti6Al4V-23\% TiC to Ti-33.8\% TiC MMC, the wear rate of $23 \%$ TiC was marginally lower than $33.8 \% \mathrm{TiC}$ coating (see Fig. 16). This could be due to the higher hardness of the Ti6Al4V-23\% TiC composite that increased the load bearing capacity and resisted plastic deformation. This indicates that despite having lower ceramic retention, by using a high strength alloy matrix, similar tribological performance as that of a high ceramic reinforced composite with pure metal as matrix could be achieved. It can be hypothesized that a further increase in ceramic retentions in IP MMCs (i.e. > 23\%) could lead to even better tribological performance. However, to increase the ceramic retention, continued optimization of the spray parameters or changing the ceramic powder morphology would be required. Secondly, the fabrication of a dense SP Ti6Al4V-TiC MMC with similar retentions i.e. $33 \% \mathrm{TiC}$, may have provided similar or better tribological performance than SP Ti-TiC. However, obtaining dense coatings using spherical powders along with higher retentions remains challenging using nitrogen as propellant gas. This could possibly be achieved by using He that accelerates particles to higher velocities, improves the metal particle deformability [49], and results in higher ceramic retentions.

Overall, this comparison of the Ti-TiC coatings [2] and the Ti6Al4V-TiC coatings studied here show that there is a set of properties (Table 2) important to engineer wear resistance for MMCs made by CS. Ideally, one desires a composite with a strong, cohesive matrix material with a 
relatively high quantity of reinforcing ceramic. All of these features would help the MMC to show positive responses to wear as outlined in Fig. 15, where there is a reduction in source flows and stability for tribolayers. In the material systems studied here, coatings made from the irregular Ti6A14V powders showed an ability to retain more ceramic particles compared to spherical Ti6Al4V powders (at similar spray conditions). These coatings showed the greatest promise, with low wear rates and the formation of stable, lubricating tribolayers. Further optimization of powder morphology and spray conditions may make it possible to achieve even higher performance from MMCs made by CS.

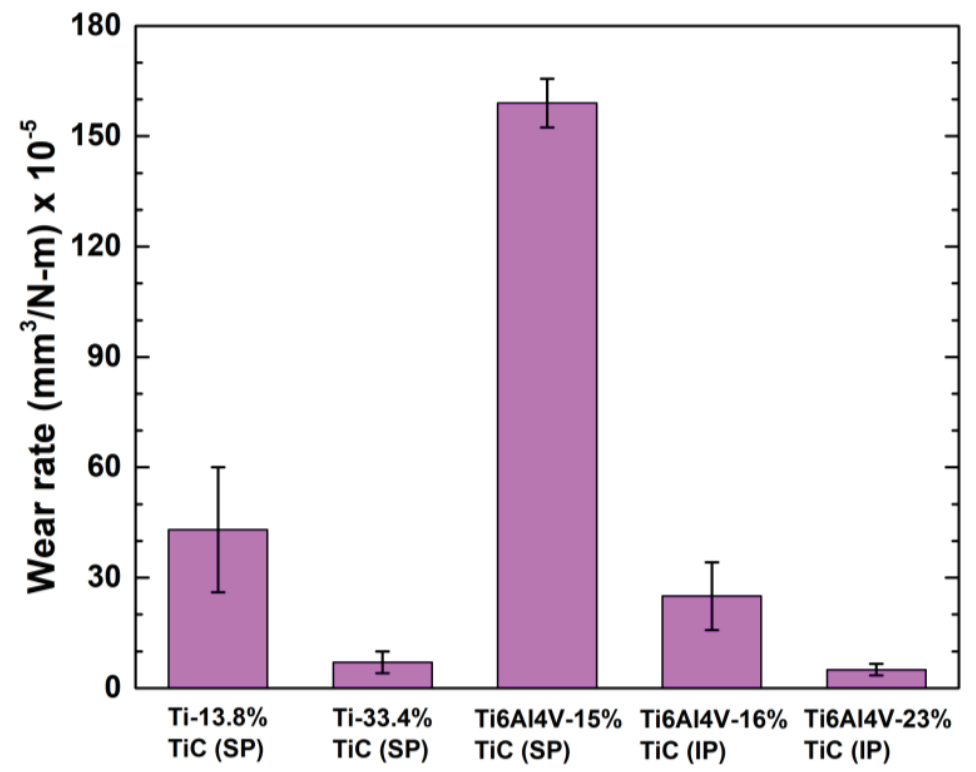

Fig. 16: Comparison between the wear rates of Ti-TiC [2] and Ti6Al4V-TiC composites at $0.5 \mathrm{~N}$ normal load. 


\section{Conclusions}

In the present study, Ti6A14V-TiC composite coatings were CS deposited using spherical and irregular Ti6A14V powders and their sliding wear behaviour was evaluated. Based on the results following conclusions were drawn:

1. Ti6Al4V-TiC MMCs deposited using irregular powders had extremely low porosity $(<2 \%)$, higher ceramic retentions, and showed better tribological properties both at low and high normal loads compared to SP composites.

2. At low loads i.e. $0.5 \mathrm{~N}$, formation of tribolayers comprising of oxides of $\mathrm{Ti}$ and fragmented TiC particles were observed on the wear tracks of IP MMCs that led to low $\mathrm{CoF}$ and wear rates. The formation of tribolayers showed twin effect of both resisting the localized deformation and facilitated for the easy shear of the counterface during sliding. However, the ease of tribolayer formation and coverage on the wear track was dependent on the TiC content in the coatings.

3. In case of SP MMCs, delamination of splats due to their poor bonding did not support the formation of tribolayers. This led to significant plastic deformation of the coating, high source flows and abrasion by the wear debris resulting in high friction and wear rates.

4. At higher loads i.e. $2.5 \mathrm{~N}$, formation of tribolayers depended on the TiC content in the coatings. Highly continuous tribolayers were observed on the wear track of $23 \%$ TiC composite coating whereas no significant tribolayers were observed on the wear tracks of $15 \%$ and $16 \% \mathrm{TiC}$ coatings. In case of $23 \% \mathrm{TiC}$ coating, higher ceramic content resulted in greater dislodging of $\mathrm{TiC}$ particles from the matrix and led to the formation of a highly continuous tribolayer. This resulted in highly stable and low $\mathrm{CoF}$ along with low wear rates.

5. Fragmentation of carbide particles during wear and their reinforcement in the tribolayers contributed to their higher hardness, while the presence of free carbon led to their lubricating nature. These two properties resulted in a composite effect by reducing the magnitude of stress transfer to the subsurface resulting in the formation of coarse grains along with lesser extent of subsurface deformation compared to the wear tracks without tribolayers.

\section{Acknowledgments}

The authors are thankful for the technical assistance from Maniya Aghasibeig and Jean-Francois Alarie at McGill Aerospace Materials and Alloy Design Centre (MAMADC). The authors 
gratefully acknowledge the contributions of Rene Cooper from Cristal Metals for providing the irregular Ti6A14V powders and Stéphanie Bessette for technical assistance with the SU8230. The authors also thank Weawkamol Leelapornpisit and David Liu at the Facility for Electron Microscopy Research of McGill University for help with the FEI Helios NanoLab 660 and FEI Tecnai G2 F20. This project would also not have been possible without the financial support from the Natural Science and Engineering Research Council (NSERC), Canada: Strategic Grants Program.

\section{References}

[1] Rasool G, Mridha S, Stack MM. Mapping wear mechanisms of TiC/Ti composite coatings. Wear 2015;328-329:498-508.

[2] Alidokht SA, Munagala VNV, Chromik RR. Role of third bodies in friction and wear of cold-sprayed Ti and Ti-TiC composite coatings. Tribol Lett 2017;65.

[3] Yamaguchi T, Hagino H, Michiyama Y, Nakahira A. Sliding wear properties of Ti/TiC surface composite layer formed by laser alloying. Mater Trans 2015;56:361-6.

[4] Zi-Run Y, Hai-Xiang H, Jiang CF, Li WM, Liu XR, Lyu S. Evaluation on dry sliding wear behavior of $(\mathrm{TiB}+\mathrm{TiC}) / \mathrm{Ti}-6 \mathrm{Al}-4 \mathrm{~V}$ matrix composite. Int $\mathrm{J}$ Precis Eng Manuf 2017;18:1139-46.

[5] Kusinski J, Kac S, Szwachta G, Dosta S, Garcia-Forgas J, Georgiou EP. Wear resistance of the Ti/TiC coatings deposited by means of supersonic cold gas spray technique. TMS 2014 Suppl Proc 2014:1173-80.

[6] Venkataraman B, Sundararajan G. Correlation between the characteristics of the mechanically mixed layer and wear behaviour of aluminium, A1-7075 alloy and Al-MMCs. Wear 2000;245:22-38.

[7] Shockley JM, Strauss HW, Chromik RR, Brodusch N, Gauvin R, Irissou E, et al. In situ tribometry of cold-sprayed Al-A12O3 composite coatings. Surf Coatings Technol 2013;215:350-6.

[8] Candel JJ, Amigó V, Ramos JA, Busquets D. Sliding wear resistance of TiCp reinforced titanium composite coating produced by laser cladding. Surf Coatings Technol 2010;204:3161-6.

[9] Ghazanfari H, Blais C, Alamdari H, Gariépy M, Savoie S, Schulz R. Characterization of dry-sliding wear of HVOF coatings made of Fe3Al powders reinforced with submicrometer TiC particles produced by combustion synthesis. Surf Coatings Technol 2019;360:29-38.

[10] Wang F, Mei J, Jiang H, Wu X. Laser fabrication of Ti6Al4V/TiC composites using simultaneous powder and wire feed. Mater Sci Eng A 2007;445-446:461-6.

[11] Chen H, Du Y, Wang D, Zhang C, Yang G, Liu B, et al. TiC/Ti3AlC2-Co plasma-sprayed 
coatings with excellent high-temperature tribological properties. Ceram Int 2018;44:225208.

[12] Alidokht SA, Vo P, Yue S, Chromik RR. Cold Spray deposition of Ni and WC-reinforced Ni matrix composite coatings. J Therm Spray Technol 2017;26:1908-21.

[13] Kim HJ, Lee CH, Hwang SY. Fabrication of WC-Co coatings by cold spray deposition. Surf Coatings Technol 2005;191:335-40.

[14] Munagala VNV, Akinyi V, Vo P, Chromik RR. Influence of powder morphology and microstructure on the cold spray and mechanical properties of Ti6A14V coatings. J Therm Spray Technol 2018;27:827-42.

[15] Koivuluoto H, Bolelli G, Milanti A, Lusvarghi L, Vuoristo P. Microstructural analysis of high-pressure cold-sprayed $\mathrm{Ni}, \mathrm{NiCu}$ and $\mathrm{NiCu}+\mathrm{Al} 2 \mathrm{O} 3$ coatings. Surf Coatings Technol 2015;268:224-9.

[16] Moridi A, Hassani-Gangaraj SM, Guagliano M, Dao M. Cold spray coating: review of material systems and future perspectives. Surf Eng 2014;30:369-95.

[17] Assadi H, Gärtner F, Stoltenhoff T, Kreye H. Bonding mechanism in cold gas spraying. Acta Mater 2003;51:4379-94.

[18] Li W, Assadi H, Gaertner F, Yin S. A review of advanced composite and nanostructured coatings by solid-state cold spraying process. Crit Rev Solid State Mater Sci 2018;8436:148.

[19] Sevillano F, Poza P, Múnez CJ, Vezzù S, Rech S, Trentin A. Cold-sprayed Ni-Al2O3 coatings for applications in power generation industry. J Therm Spray Technol 2013;22:772-82.

[20] Degnan CC, Shipway PH, Wood JV. Elevated temperature sliding wear behaviour of TiCreinforced steel matrix composites. Wear 2002;251:1444-51.

[21] Chawla N, Chawla KK. Metal matrix composites. 2nd ed. Springer New York Heidelberg Dordrecht London; 1991.

[22] Yin S, Ekoi EJ, Lupton TL, Dowling DP, Lupoi R. Cold spraying of WC-Co-Ni coatings using porous WC-17Co powders: Formation mechanism, microstructure characterization and tribological performance. Mater Des 2017;126:305-13.

[23] Shockley JM, Descartes S, Vo P, Irissou E, Chromik RR. The influence of A12O3 particle morphology on the coating formation and dry sliding wear behavior of cold sprayed AlAl2O3 composites. Surf Coatings Technol 2015;270:324-33.

[24] A. Alidokht S, Yue S, Chromik RR. Effect of WC morphology on dry sliding wear behavior of cold-sprayed Ni-WC composite coatings. Surf Coatings Technol 2019;357:849-63.

[25] Vardavoulias M. The role of hard second phases in the mild oxidational wear mechanism of high-speed steel-based materials. Wear 1994;173:105-14.

[26] Fernandez R, Jodoin B. Cold Spray Aluminum-Alumina Cermet Coatings: Effect of Alumina Content. J Therm Spray Technol 2019;27:603-23.

[27] Munagala VNV, Torgerson TB, Scharf TW, Chromik RR. High temperature friction and wear behavior of cold-sprayed Ti6Al4V and Ti6Al4V-TiC composite coatings. Wear 
2019;426-427:357-69.

[28] Melendez NM, Narulkar V V., Fisher GA, McDonald AG. Effect of reinforcing particles on the wear rate of low-pressure cold-sprayed WC-based MMC coatings. Wear 2013;306:185-95.

[29] Oliver WC, Pharr GM. An improved technique for determining hardness and elastic modulus using load and displacement sensing indentation experiments. J Mater Res 1992;7:1564-1583.

[30] Grigoriev S, Okunkova A, Sova A, Bertrand P, Smurov I. Cold spraying: From process fundamentals towards advanced applications. Surf Coatings Technol 2015;268:77-84.

[31] Dong H, Bell T. Tribological behaviour of alumina sliding against Ti6Al4V in unlubricated contact. Wear 1999;225-229:874-84.

[32] Godet M. Third-bodies in tribology. Wear 1990;136:29-45.

[33] Berthier Y, Godet M, Brendle M. Velocity accommodation in friction. Tribol Trans 1989;32:490-6.

[34] Shockley JM, Descartes S, Irissou E, Legoux JG, Chromik RR. Third body behavior during dry sliding of cold-sprayed Al-Al2O3composites: In situ tribometry and microanalysis. Tribol Lett 2014;54:191-206.

[35] Alidokht SA, Manimunda P, Vo P, Yue S, Chromik RR. Cold spray deposition of a Ni-WC composite coating and its dry sliding wear behavior. Surf Coatings Technol 2016;308:42434.

[36] Goldbaum D, Ajaja J, Chromik RR, Wong W, Yue S, Irissou E, et al. Mechanical behavior of Ti cold spray coatings determined by a multi-scale indentation method. Mater Sci Eng A 2011;530:253-65.

[37] Vo P, Irissou E, Legoux JG, Yue S. Mechanical and microstructural characterization of cold-sprayed Ti-6Al-4V after heat treatment. J Therm Spray Technol 2013;22:954-64.

[38] Molinari A, Straffelini G, Tesi B, Bacci T. Dry sliding wear mechanisms of the Ti6A14V alloy. Wear 1997;208:105-12.

[39] Straffelini G, Molinari a. Dry sliding wear of Ti-6Al-4V alloy as influenced by the counterface and sliding conditions. Wear 1999;236:328-38.

[40] Munagala VNV, Bessette S, Gauvin R, Chromik RR. Sliding wear of cold sprayed Ti6A14V coatings : Effect of porosity and normal load. Wear 2020;451.

[41] Mao YS, Wang L, Chen KM, Wang SQ, Cui XH. Tribo-layer and its role in dry sliding wear of Ti-6Al-4V alloy. Wear 2013;297:1032-9.

[42] Cui XH, Mao YS, Wei MX, Wang SQ. Wear Characteristics of Ti-6Al-4V Alloy at 20$400^{\circ} \mathrm{C}$. Tribol Trans 2012;55:185-90.

[43] Zhang QY, Cui XH, Wang L, Li XX, Wang SQ, Chen KM. Comparative study of wear behaviors of a selected titanium alloy and AISI H13 steel as a function of temperature and load. Tribol Trans 2014;57:838-45.

[44] Chromik RR, Alidokht SA, Shockley JM, Zhang Y. Tribological coatings prepared by cold spray. Cold-Spray Coatings, 2018, p. 321-48. 
[45] Hamilton GM. Explicit equations for the stresses beneath a sliding spherical contact. Proc Inst Mech Eng Part C J Mech Eng Sci 1983;197:53-9.

[46] Straffelini G. Friction and wear : Methodologies for design and control. Springer; 2015.

[47] Richerson DW, Carruthers WD, Lindberg LJ. Contact stress and coefficient of friction effects on ceramic interfaces. Surfaces Interfaces Ceram. Ceram. - Met. Syst., 2012, p. $661-76$.

[48] Munagala VNV, Imbriglio SI, Chromik RR. The influence of powder properties on the adhesion strength and microstructural evolution of cold sprayed Ti6Al4V single splats. Mater Lett 2019;244:58-61.

[49] Wong W, Irissou E, Ryabinin AN, Legoux JG, Yue S. Influence of helium and nitrogen gases on the properties of cold gas dynamic sprayed pure titanium coatings. J Therm Spray Technol 2011;20:213-26. 